\title{
Novel laboratory investigation of huff-n-puff gas injection for shale oils under 2 realistic reservoir conditions
}

Pedram Mahzari ${ }^{1}$, Thomas M. Mitchell ${ }^{1}$, Adrian P. Jones ${ }^{1}$, Eric H. Oelkers ${ }^{1}$, Alberto Striolo ${ }^{2}$, Francesco Iacoviello $^{2}$, Paul R. Shearing ${ }^{2}$, Juan Ernesto Juri ${ }^{3}$

${ }^{1}$ Department of Earth Sciences, University College London

${ }^{2}$ Departmen of Chemical Engineering, University College London

${ }^{3} Y P F S A$

\section{Abstract}

Enhanced oil recovery (EOR) from shale oil formations is recognized as the next frontier in the exploitation of unconventional resources. Current approaches for performing EOR experiments using fractured rocks can generate misleading results as the fractured cores cannot be saturated with live oils. In this work, a novel laboratory methodology is developed to quantify the efficiency of gas huff-n-puff in shale oil formations under realistic reservoir conditions, i.e. live oil and hydraulic fracturing reservoir conditions. This new approach involves first saturating the shale core with oil and then hydraulic fracturing the oil-saturated core by increasing pore pressure above the core confining pressure. To demonstrate the viability of this new methodology, shale cores from the Haynesville formation with a permeability of $0.0001 \mathrm{mD}$ were tested.

Two huff-n-puff experiments were performed by the injection of associated gas into cores saturated with either dead crude oil or live oil. $48 \%$ additional oil recovery was achieved from the shale core saturated with live oil whereas, the shale core saturated with dead oil yielded a $33 \%$ enhanced oil recovery, which is significantly lower than that of the live oil. Furthermore, the pressure decay profiles during the soaking periods indicate a comparatively higher gas penetration into the live oil system despite the higher gas solubility in the dead oil. The in-situ gas formation can have a strong influence on the efficiency of huffn-puff. The notable differences in the results obtained on live compared to dead oil experiments demonstrate the need to perform more realistic laboratory experiments to better optimize shale oil EORbased extractions in the field.

\section{Introduction}

Gas injection for enhanced oil recovery (EOR) in unconventional liquid-rich reservoirs such as shale oils has become attractive for stakeholders in the industry and academia because primary depletion recovers less than $10 \%$ of the original oil in place ${ }^{1-7}$. Production from shale oil resources requires drilling a large number of wells, and then stimulating them by extended and multi-stage hydraulic fracturing ${ }^{8}$. The production period of fracked wells is short due to their limited drainage area ${ }^{9}$. Increasing oil recovery from existing wells in tight formations can obviate the need for re-fracking, which alleviates some environmental concerns. Due to their fundamental differences compared to conventional reservoirs, EOR techniques on shale oil resources require tailored implementation of the fundamental physics underlying fluid flow in ultra-tight rocks ${ }^{10}$. Among the proposed EOR methods, gas-based injection scenarios have been explored since gas injection can be more readily achieved in tight rocks compared to liquids due to their favorable viscosity ${ }^{2,11,12}$. Oil swelling and viscosity reduction have been previously proposed as the mechanisms leading to additional oil recovery ${ }^{2,13-16}$. In addition, injecting hydrocarbon gases or $\mathrm{CO}_{2}$ into underground geological formations has the advantage of attenuating carbon emissions ${ }^{17-19}$, which can alleviate the current problem of flaring for shale oil operators ${ }^{20}$. The gas released or flared during shale 
44 oil operations has become of increasing concern ${ }^{21}$. Both capturing these gases and using them for EOR 45 has the economic benefit of increasing the resource extraction and the environmental benefits of reducing 46 the greenhouse gas emissions ${ }^{22}$.

47 The pore-scale mechanisms controlling gas transport in liquid-rich shales, however, are not well understood. The interactions between reservoir fluids in nano-porous shale formations have been scarcely studied experimentally, particularly under reservoir conditions. Laboratory experiments are therefore useful in order to identify the processes occurring during gas injection in shale formations under controlled conditions $^{23-27}$. Although pilot tests on natural oil-bearing systems can directly provide an estimate of the effectiveness of an EOR method, comparative studies may not be feasible ${ }^{2,14,15}$. Another limitation of pilot studies is their cost. The cost of pilot studies can be in excess of several millions US dollars, whereas laboratory experiments can be conducted at significantly lower $\operatorname{costs}^{28,29}$. On the other hand, there are significant differences between EOR efficiencies generated from laboratory experiments and those found by field observations ${ }^{12,2}$. Several previous laboratory experiments have reported remarkable oil recoveries up to $90-100 \%$, yet the average oil recoveries in field scale huff-n-puff pilots are around $30 \%{ }^{30,31}$. Improved methodologies enabling a more realistic evaluation of EOR methods in laboratories are clearly needed. In this work, a new laboratory methodology is presented and applied to better reproduce EOR at in-situ reservoir conditions, highlighting the importance of performing laboratory experiments under full reservoir conditions in tight shale formations.

Previous laboratory studies of gas huff-n-puff injections into shale oil systems have considered reduced conditions where the oil phase did not contain dissolved gases ${ }^{25,32,33}$. Some recent studies have attempted to simulate enhanced oil recovery from matrix-fracture combinations in shale reservoirs by installing high permeability spacers on core surfaces to represent fractures ${ }^{34}$. Other laboratory experiments were designed to house a pre-saturated core in a high-pressure vessel and then introduce the gas to surround the core ${ }^{35,36}$. Such studies are not capable of replicating reservoir conditions where the shale matrix is saturated with 68 live oil. Live oil is defined as an oil phase at high pressure that contains some dissolved gas, whereas dead oil refers to crude oils at ambient conditions after its dissolved gas was released. Performing experiments with live oils is challenging, due to the fact that injecting live oil into a pre-fractured porous media leads to the flow of the oil through the fractures bypassing the rock matrix ${ }^{37}$. Current laboratory methodologies are designed to expose all rock surfaces of the matrix to the gas, which does not mimic field processes where the gas enters the rock via a network of branching fractures and is then transported into the matrix. This may be the reason why laboratory studies commonly exhibit additional oil recoveries of more than 90\% during EOR experiments, compared to natural systems where the recovery is far less. In decades, 
reservoirs ${ }^{38}$. Such challenges demonstrate the need for new laboratory approaches capable of replicating full reservoir conditions that accurately replicate EOR in fracked shale oil reservoirs, as well as in conventional naturally fractured reservoirs.

Despite the lack of laboratory studies under full reservoir conditions, several numerical simulations demonstrate the importance of using realistic reservoir conditions ${ }^{39-41}$. Such numerical simulations, 82 however, require input parameters obtained from experimental observations ${ }^{42}$. Hence, laboratory experiments under full reservoir conditions are essential. To physically replicate realistic reservoir conditions for shale formations, it is necessary to inject high-pressure fluids into tight matrix cores and then create fractures while the cores are kept at elevated pressure in-situ. This is not possible using currently available coreflood experimental methods ${ }^{27,43}$.

The importance of using live oil over dead crude oil in such experiments stems from the fundamental characteristics of reservoir fluids and their impact on the diffusive flow of gas into shale oil formations. The viscosity of live oil is notably lower than that of dead oils. In addition, the gas diffusion coefficient is higher in fluids having lower viscosities. The interfacial tension between oil and injected gas is significantly affected by the amount of dissolved gas in the $\mathrm{oil}^{44}$. Various studies have highlighted the importance of interfacial tension between the oil and the injected gas on EOR efficiency in fractured shale reservoirs ${ }^{45,46}$. Furthermore, gas huff-n-puff in shales can lead to gas dissolution into the oil and hence, the pressure reduction can generate gas bubbles that can help push oil out of pore spaces ${ }^{47}$. This process can be controlled by the solution gas ${ }^{48}$. Therefore, using dead oil in huff-n-puff experiments overlooks some of the underlying mechanisms behind the additional oil recovery.

Once the pore pressure exceeds the confining pressure in conventional coreflood experiments, the experiment usually fails. This makes it difficult, if not impossible, to fracture the rock during a laboratory experiment via conventional approaches. To overcome this limitation, a novel experimental approach has been developed in this study, where the coreflood apparatus is modified to allow pore pressures higher than confining pressures and hence, the rock can be hydraulically fractured in-situ. This method allows replication of the production scenarios for shale oil reservoirs whereby (i) the rock is saturated with live oil, then (ii) fracking is performed by increasing pore pressure above the confining pressure, and then (iii) huff-n-puff cycles are performed. To examine the benefits of this new design, two experiments were performed; the first was gas huff-n-puff in a shale core saturated with a live oil, and the second in a shale core saturated with a dead oil. Comparing the two experiments provides new insight into the EOR efficiencies for shale oil formations. The data generated from the experiments can also be used to finetune parameters for upscaling the observed processes to field applications. 


\section{Experimental approach}

Figure 1 illustrates schematically the experimental apparatus used for the coreflood experiments in this study. One important feature of this apparatus is the hydraulic pressure intensifiers with tuned closed loop servo control that can respond swiftly to pressure changes. Fracking requires abrupt pressure changes.

114 Fluid volume and pressure measurements are the main sources of data uncertainty in such experiments. Volume measurements of liquid phases were carried out via a glass collector with an accuracy of $\pm 0.1 \mathrm{ml}$, while gas volume readings have an accuracy of $\pm 10 \mathrm{ml}$ at ambient conditions. The tubing and dead volumes of the experimental apparatus were minimized using narrow $\left(\frac{1}{16}\right.$ ") bore-size tubing and pressure was measured to within $\pm 0.25 \%$ of the measurement range using pressure transducers.

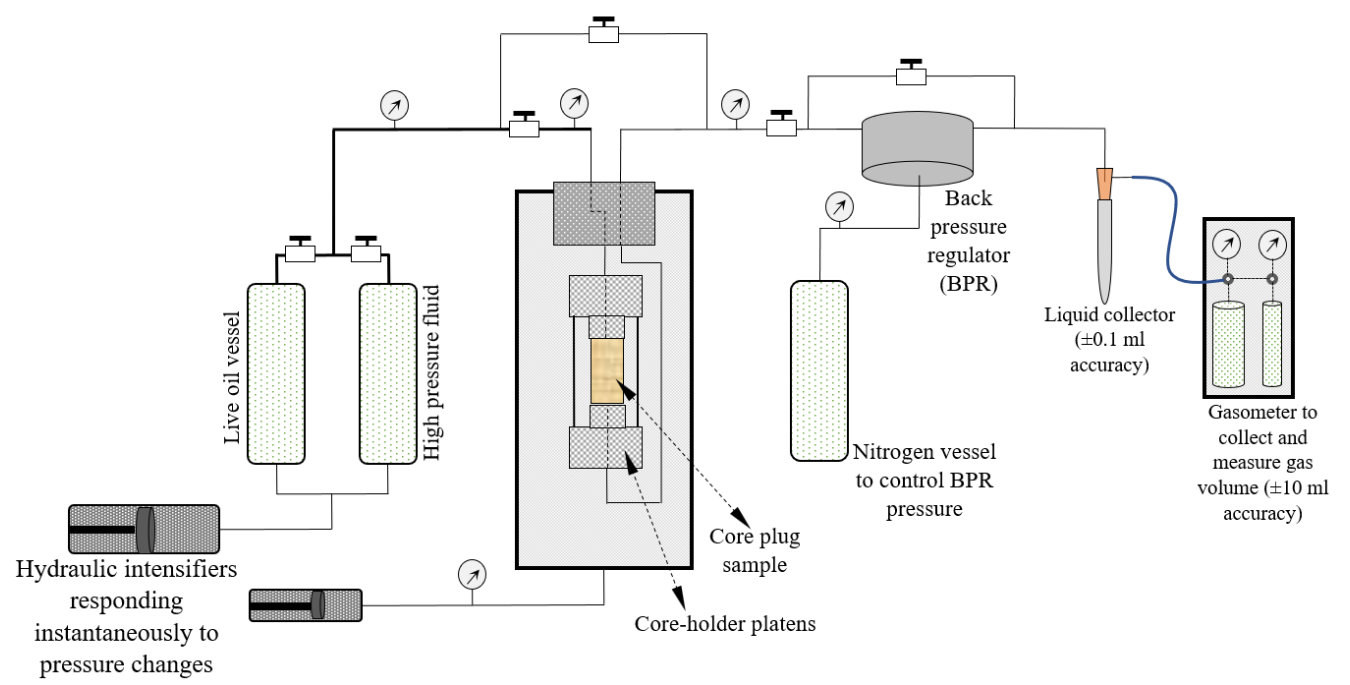

Figure 1. Schematic illustration of the bespoke coreflood apparatus used for the experiments presented in this study.

In conventional coreflooding experiments, cylindrical cores are generally wrapped within a jacket to confine the injected fluid within the pores. Typically, the confining pressure is set $500 \mathrm{psi}$ above the injection pressure. If the injection pressure exceeds the confining pressure, the sealing capacity of the core jacket is impaired, and the experiment fails. To perform coreflood experiments where the injection pressure is significantly higher than confining pressure, such as those that involve in-situ fracking, the design of the jacket sealing and end-platens need to be modified. Figure 2-a depicts the modified coreholder that can operate under hydraulic fracturing conditions. This modified design was inspired by that proposed by Rutter and Hackston ${ }^{49}$. This fracking technique, where a hole is dilled in shale samples, was employed in some previous studies ${ }^{50}$. The current study is, however, the first to couple experimental approaches of hydraulic fracturing and EOR. The top platen, made from Hastelloy steel, was grooved to house a number of sealing o-rings that can separate the injected fluid from the core jacket. A sealing spacer 
machined from Viton. If the sealing capability of O-rings was compromised, the injected gas could interact with the top face of the core, which could potentially affect the results. To prevent this possibility, an additional sealing spacer was introduced in our experimental design (see Figure 2).

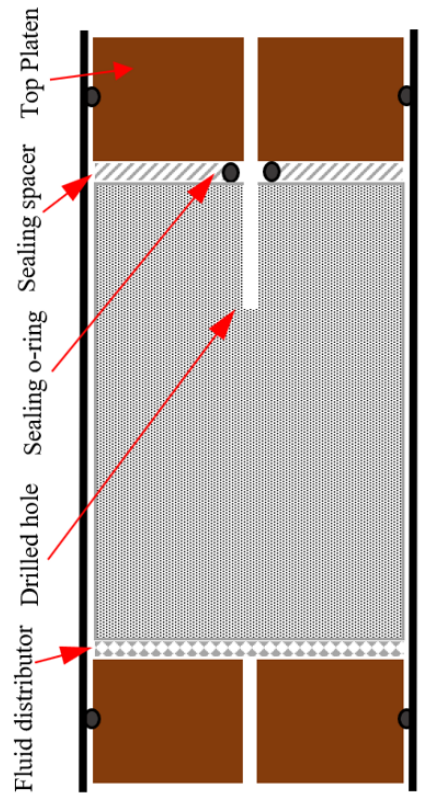

(a)

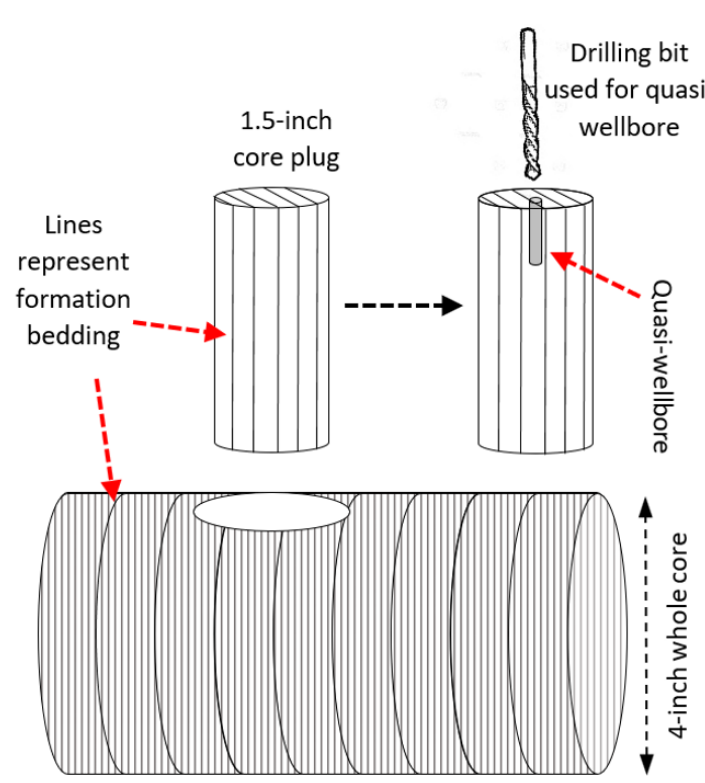

(b)

Figure 2: (a) Design of the core-jacket sealing assembly for the fracking and huff-n-puff experiments presented in this study. (b) Shale cores oriented along their bedding are drilled with a quasi-wellbore to aid in the fracking. The top of the core is sealed, enabling increasing the injection pressure above the confining pressure. Illustration (b) shows the core drilled along the geological bedding of the original whole rock sample. The shale sedimentary bedding orientation is indicated by black lines on the core samples. The upper cores are used in the experiment, but the lower core shows the orientation of the original whole core obtained from the shale reservoir.

Having modified the core-holder and jacketing system, the core sample required a hole, referred to as the quasi-wellbore in what follows, drilled into the top of the core to physically simulate a well drilled in shale reservoirs (as illustrated in Figure 2-b) and allow the pore fluid to immediate reach the center of the sample during injection ${ }^{49,50}$. The quasi-wellbore is necessary to direct the injected fluid into the core instead of the sealing o-rings, which then initiates fracture formation during hydraulic fracturing. The depth of the quasi-wellbore is $25 \%$ of the core length and its diameter is around $5 \%$ of the core diameter. The diameters and depth of the quasi-wellbore are adjusted to secure the sealing between the core and the jacket. As injection-induced fractures tend to form along the bedding direction of the shale rocks ${ }^{51-53}$, the cores used in this study were cut along the bedding of the shale formation (as highlighted in Figure 2-b). It should be noted that this experimental methodology is designed to create a single bedding-parallel fracture spreading from the inlet of the core to its outlet as verified below, and cannot be employed for fracking in a direction normal to shale bedding. Due to their complex geometry, multiple complex fractures in various directions would not be appropriate for analytical and numerical studies of the experiments as results would be challenging to rigorously interpret. Fracture formation was verified by 
measuring the core permeability after fracking. Note that, in the field case studies the fractures are formed normal to the wellbore orientation in field studies, which is different from that in this laboratory study. Our objective, however, is to replicate the general realistic conditions of huff-n-puff in any fracture-matrix unit, which can then be upscaled for shale oil systems irrespective of wellbore configurations.

\section{Methodology}

The experiments were designed to first saturate the shale core with an oil and then, hydraulically fracture the core in-situ. The resulting fracked core can thus be considered as a close analog to field EOR methods. After mounting the core into the modified coreflood apparatus, it is pressurized with helium up to the working pressure. Next, the core was pressurized to the bubble point pressure of the live oil, i.e. $1800 \mathrm{psi}$. The pressurization process was monitored with two pressure transducers located at both ends of the core. Helium is injected from one side of the core at constant pressure. Once the other end of the core reaches the injection pressure, the helium source is disconnected, and pressure profiles are recorded. The core is assumed to be uniformly pressurized if the pressure remains constant for one day.

Oil is subsequently injected from the bottom of the core. As illustrated in Figure 3-a, the fluid distributor at the bottom of the core leads to a uniform injection of the oil. Oil injection is carried out under high effective stress, which is defined as the difference between confining pressure and average pore pressure. This ensures that the injected oil can penetrate into the tight core matrix. As the oil travels through the core, the flow streamlines move towards the quasi-wellbore. This could lead to the top corner edges of the core being bypassed by the oil. To alleviate this possibility, the initial injection is followed by a sequence of multiple inject-soak-inject stages. Each soaking period for the oil injection is one week. After the soaking period, 1.2 pore volumes of oil were injected and the gas oil ratio (GOR) of the effluent is measured and compared against that of the original oil GOR.

After saturating the core with oil, both ends of the core were opened to the back-pressure regulator (BPR in Figure 1) and the pressures were allowed to stabilize for one day. Subsequently, the confining pressure was reduced to $250 \mathrm{psi}$ above the $1800 \mathrm{psi}$ pore pressure to prepare the core for fracking. The oil in the high-pressure vessel was then pressurized to $8000 \mathrm{psi}$, i.e. the fracking pressure. As depicted in Figure 3-b, the fracking fluid (in this case oil) was allowed to invade the top of the core entering via the quasi-wellbore for 5-10 seconds to create the fracture. Note that the bottom of the core is connected to a back-pressure regulator and hence, as soon as the fracture is created (i.e., a path is established between top and bottom of the core), the pressure of the inlet drops to that of the back pressure regulator. If the imposed pressure conditions could not create the fracture in 5-10 seconds, the sealing O-rings at the top of the core may be impaired. After the in-situ fracking of the core, the permeability of the core with the fracture is measured under various stress conditions. 


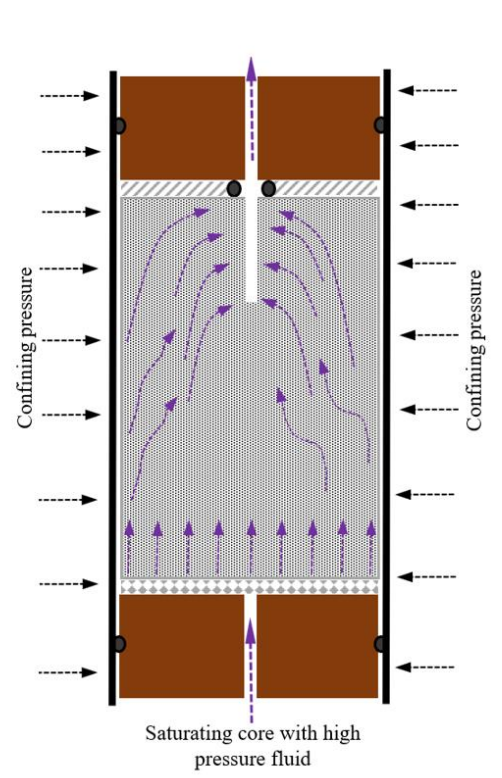

(a)

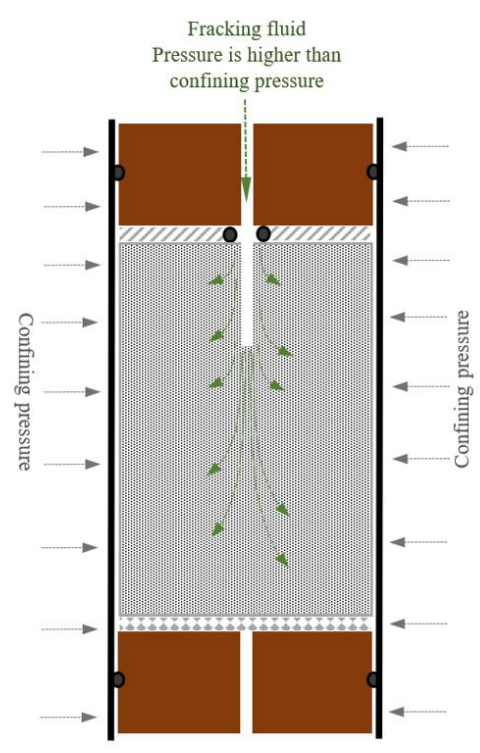

(b)

Figure 3: (a) Schematic illustration of the shale core and flow streamlines during oil injection. The confining pressure is significantly higher than the injection pressure to ensure closure of microfractures. (b) Flow direction and flow streamlines during the fracking of the core. The confining pressure is significantly lower than the injection pressure, which leads to crack formation connecting the top to the bottom of the core.

Coreflood apparatuses are commonly characterized by relatively high dead volumes, including the volume of tubing and valves, which may introduce significant uncertainties to measured results. To avoid such issues, once the core was fractured, gas was injected under very low effective stress from the top to displace the oil present in the tubing and the fracture. This process was performed as fast as possible to reduce the interaction time between the injected gas and the oil in the matrix. For the oil remained in the fracture as a wetting layer after the gas injection, the wetting layer with thickness of 10 micron, the trapped oil volume is $0.04 \mathrm{ml}$, which is negligible in our calculations. As we have displaced the bulk of the liquid phase in the fracture, the remaining wetting liquid can be insignificant in our analysis. Further, the amount of wetting film 'left over' should be comparable for the two datasets (i.e. live and dead oil tests), hence this uncertainty does not alter the conclusions of the study. After this, the core is ready for huff-n-puff cycles. The confining pressure is then increased to $250 \mathrm{psi}$ above $8000 \mathrm{psi}$ injection pressure. Then, the gas is injected at constant pressure for 5 minutes under 250 psi effective stress, which is followed by a shut-in period where the source of gas injection is disconnected from the core and the gas is allowed to be soaked. The pressure decay profile is measured as an indicator of the gas invasion-diffusion processes. After the soaking period, the core is depressurized to the initial working pressure of $1800 \mathrm{psi}$, and the produced oil and gas volumes are measured. To collect the oil produced from each huff-n-puff cycle, a fast gas injection period under low effective stress is performed to displace the oil in tubing and the fracture. To demonstrate the advantages of this new methodology, two experiments were performed using the same rock type, one with live oil and one with dead oil. 


\section{Rock and Fluids Properties}

The physical properties of shale cores used for the experiments are shown in Table 1. The cores were taken from a block of Haynesville shale formation extracted in the Caspiana field from a depth of 11750 $\mathrm{ft}^{54}$. To measure the Swi (interstitial water saturation) of this shale, four core samples from the shale block were heated to $200{ }^{\circ} \mathrm{C}$, which led to the average Swi of $11 \pm 1.3 \%$. For Swi measurement, cores and crushed rocks were heated in a closed container and the vapor phase was cooled to collect the condensed water to convert to Swi. Also, the samples were weighed before and after the heating to verify the results. For the cores used in the experiments, we did not perform the heating process as it could alter the rocks. We attempted to estimate the Swi by micro-CT imaging, but the error was high. Therefore, we decided to use intact cores for the tests, which makes the experiments representative to field cases, considering the average Swi of other four samples. Note that the standard deviation of the Swi is not significantly high for the samples, which indicates a fairly homogeneous distribution of the Swi within the block. Two cores, 1.5 inches in diameter, were sampled close together (i.e., $1 \mathrm{~cm}$ away from each other) to produce comparable results. Utilizing helium pycnometry, the cores were found to have an average porosity of 8\%. The matrix permeability was measured by helium injection under steady-state flow using Darcy's law. To measure the absolute permeability of the cores using the apparatus illustrated in Figure 1, one of the high-pressure vessels was charged with helium, and then helium was injected through the core under constant pressure. The injected helium was produced through the back-pressure regulator. Once the injection flow rate became steady and a constant gas production was measured on the gasometer, Darcy's law was used to calculate the permeability. Slippage (i.e., the Klinkenberg effect) can interfere with geomechanical effects, e.g. stress-dependent permeability, as both are pressure dependent. We did not measure permeability under different pressures to obtain Klinkenberg corrections. The core samples were highly laminated with clay-rich mineralogy comprising of carbonates, quartz, clays, organic matter, and pyrite (see Table 2), which may contribute differently to the flow of hydrocarbon components ${ }^{55,56}$.

SEM images were recorded along the core length and combined with micro-CT X-ray imaging to characterize micro-fractures along the bedding orientation (Figure 4). Figure 4-a and -b depict SEM images of a polished piece of the shale sample. The white spots on the SEM images correspond to pyrite; the grey regions indicate quartz and carbonates, while the dark regions denote void porosities. Some of the micro-fractures have silicate fillings. Figure 4-b also shows that the micro-fractures are connected, creating highly laminated rock samples. Figure 4-e exhibits the micro-fractures that are identifiable on the exterior surface of the shale core used in EOR-1 experiment. A chip from the top edge of this core was used for micro-CT X-ray imaging using a micron-scale Zeiss Xradia 520 Versa instrument ${ }^{57}$. Figure 4-c shows a micro-CT image of this core chip while Figure 4-d depicts the same image with the void and fractures highlighted in red, which was obtained from segmented volume image with voxel size of 
$1000 \times 1000 \times 1500$. As can be seen, the micro-fractures are distributed along the formation bedding, which impacts the fracking process significantly. From analyzing the micro-CT images, we estimate that the sample has an average micro-fracture porosity of $2.5 \%$.

The properties of the live and dead crude oils used in the experiments are summarized in Table 3. The multicomponent gas injected into the cores was composed of $91 \%$ methane, $4.4 \%$ ethane, $0.4 \%$ propane, $2.3 \%$ carbon dioxide, and $1.1 \%$ nitrogen (all in weight percent). No liquid condensate was collected when the multi-component gas was flashed. Consequently, the volume of oil produced from EOR will not be influenced by condensable components of the gas. Note that the same gas was used for recombining with the oil and for the huff-n-puff cycles. This replicates the recycling of associated natural gas during commercial field-scale EOR operations. The solution gas oil ratio, oil formation volume factor and viscosity of the live oil were measured at $1800 \mathrm{psi}$, which is the production pressure. The solution gas oil ratio of the live oil was also measured at $8000 \mathrm{psi}$, which is injection pressure, to quantify the mass of gas transfer into the oil. The gas was added to the dead oil at the pressures listed in Table 3 . The gas saturated oil was then brought to standard conditions (i.e. room pressure and temperature in our laboratory) to measure the quantity of dissolved gas, which is reported as the solution gas oil ratio. Such data can help understand the amount of gas dissolvable into the oil at huff (8000 psi) and puff pressures (1800 psi).

Table 1: Basic shale core physical properties

\begin{tabular}{|l|l|l|l|c|}
\hline & Weight $(\mathbf{g r})$ & Length $(\mathbf{c m})$ & Porosity (frac.) & Matrix perm (mD) @ eff. stress of 5000 psi \\
\hline Core-1 & 210.32 & 7.52 & 0.085 & $8.76 \times 10^{-5}$ \\
\hline Core-2 & 204.12 & 7.40 & 0.092 & $5.80 \times 10^{-5}$ \\
\hline
\end{tabular}

Table 2: Mineralogical composition of the core used in this study, assuming it is equivalent with published data for samples from the same borehole at similar depths ${ }^{58-60}$.

\begin{tabular}{|l|l|l|l|c|c|c|c|c|}
\hline & $\begin{array}{l}\text { TOC } \\
(\mathbf{w t} \%)\end{array}$ & $\begin{array}{l}\text { Carbonates } \\
(\mathbf{w t} \%)\end{array}$ & $\begin{array}{l}\text { Quartz } \\
(\mathbf{w t} \%)\end{array}$ & Illite (wt\%) & Kaolinite (wt\%) & $\begin{array}{c}\text { Pyrite (wt\%) } \\
\begin{array}{l}\text { Plagioclase } \\
(\mathbf{w t} \%)\end{array}\end{array} \begin{array}{c}\text { Chlorite } \\
(\mathbf{w t} \%)\end{array}$ \\
\hline $\begin{array}{l}\text { Haynesville } \\
\text { shale } \\
\text { sample }\end{array}$ & 3.4 & 32 & 20 & 28 & 1 & 3.9 \\
\hline
\end{tabular}

271 Table 3: Properties of the live and dead oils used in the experiments. The oil formation volume factor is defined as the oil 272 volume at reservoir (or core) conditions divided by oil volume at room conditions.

\begin{tabular}{|l|l|l|c|}
\hline Pressure (psi) & $\begin{array}{l}\text { Solution gas oil ratio } \\
\text { (ccGas/ccOil) }\end{array}$ & $\begin{array}{l}\text { Oil formation } \\
\text { volume factor }\end{array}$ & Oil Viscosity (cp) \\
\hline $\begin{array}{l}\text { Dead Oil at } 1800 \mathrm{psi} \\
\text { and } 115^{\circ} \mathrm{C}\end{array}$ & $\mathbf{0}$ & $\mathbf{1 . 0 2}$ & $\mathbf{0 . 8}$ \\
\hline $\begin{array}{l}\text { Live oil saturated at } \\
1800 \text { psi and } 115^{\circ} \mathrm{C}\end{array}$ & 55.60 & 1.25 & 0.3 \\
\hline $\begin{array}{l}\text { Live oil saturated at } \\
8000 \text { psi and } 115^{\circ} \mathrm{C}\end{array}$ & 266.21 & -- & -- \\
\hline
\end{tabular}




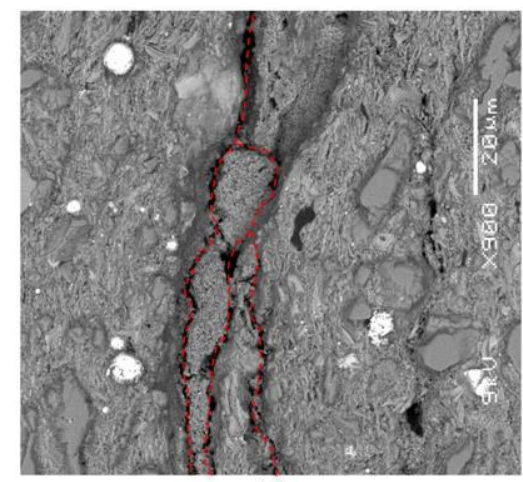

(a)

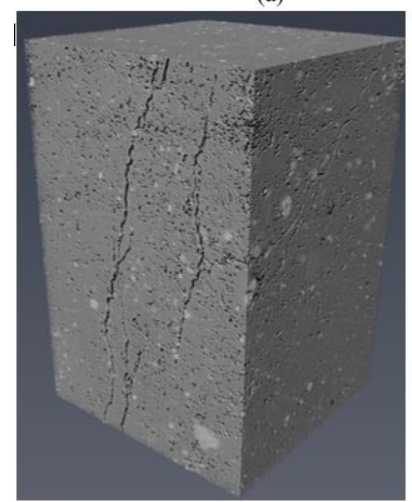

(c)

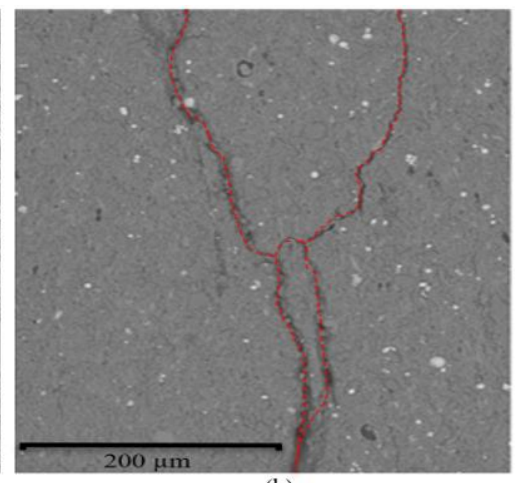

(b)

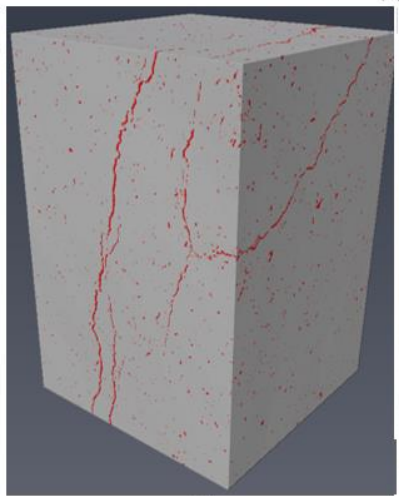

(d)

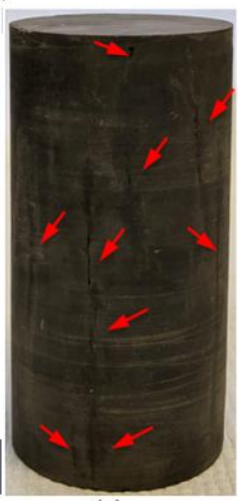

(e)

Figure 4: Observations of the shale core used for EOR-1 experiment. (a) SEM image of a rock chip taken from the top edge of the core, which indicates that the micro-fractures are filled with silicate and carbonate minerals. (b) SEM image of a microfracture located on the top edge of the core, (c) 3D perspective micro-CT X-ray image of the core cut from top. (d) segmented volume micro-CT image; the void porosity and micro-fractures as highlighted in red. (e) photograph of the entire core sample $(7.52 \mathrm{~cm}$ long, 1.5 inch diameter). Note the core has visible subvertical microfractures highlighted by red arrows, subparallel to the primary sedimentary laminations.

\section{Results and discussion}

\subsubsection{Results of experiment EOR-1: Enhanced recovery of live oil}

The first experiment was performed to determine the EOR efficiency of the gas injection over seven cycles. The live oil used for this experiment was made by recombining crude oil with its associated gas at $1800 \mathrm{psi}$ and $115^{\circ} \mathrm{C}$. This was done by placing $150 \mathrm{~cm}^{3}$ of the crude oil in a high-pressure vessel topped with $5 \mathrm{~cm}^{3}$ of the gas. The vessel was shaken intermittently to mix the gas and the oil at constant volume; the $5 \mathrm{~cm}^{3}$ gas cap in the vessel ensures equilibrium between the oil and gas. Once the pressure dropped due to gas dissolution, the vessel was again charged with the gas and the process was repeated to achieve equilibrium at $1800 \mathrm{psi}$ and $115{ }^{\circ} \mathrm{C}$. Subsequently, the gas in the vessel was removed at the constant pressure of $1800 \mathrm{psi}$ to recover the single-phase live oil. The GOR and formation volume factor were then measured to verify that gas-oil equilibrium was achieved.

The oil was injected into the pressurized shale core to displace helium. Figure 5 depicts the results of effluent GOR and effective stress measurements on the core as the oil was injected. Initially, the GOR of the effluent is relatively high as the core contains helium. Since the flow through the tight shale is slow, it is conceivable that the live oil can dissolve some helium; as the oil was recombined with the gas at 1800 
psi and the injection pressure is $2500 \mathrm{psi}$, the oil is undersaturated with respect to gases such as helium. After three pore volumes were injected, the GOR dropped to $\sim 100 \mathrm{~cm}^{3} \mathrm{Gas} / \mathrm{cm}^{3} \mathrm{Oil}$, which is approximately twice the original oil GOR. Once five pore volumes of live oil were injected, the effective stress was increased to 6200 psi by increasing the confining pressure and then four cycles of inject-soakinject were performed (as highlighted in Figure 5). As can be seen in Figure 5, the first two consecutive soaking periods resulted in a noticeable increase in the GOR, suggesting the dissolution of helium into the oil. After 11 pore volumes of live oil injection and four periods of inject-soak-inject, the effluent GOR approximately matched that of the original live oil GOR, which implies that the core was saturated with oil. To confirm that the core was saturated, a material balance was performed for the injected and produced oil. The difference between injected and produced fluid (called material balance) yields the amount of oil remained in the core. If the material balance calculation matches the pore volume, it indicates that the core is saturated with oil. In experiment 1 , the material balance conducted for live oil is $4.21 \%$ less than that of the pore volume, which is an acceptable error in this ultra-tight rock. The original oil in place (OOIP) was estimated based on material balance calculations as well, yielding results comparable to the volumetric estimate of the pore volume obtained from the Swi. After the core was saturated with the live oil, the oil pressure in the vessel was increased to 8000 psi and the confining pressure was reduced to 2050 psi to frack the core.

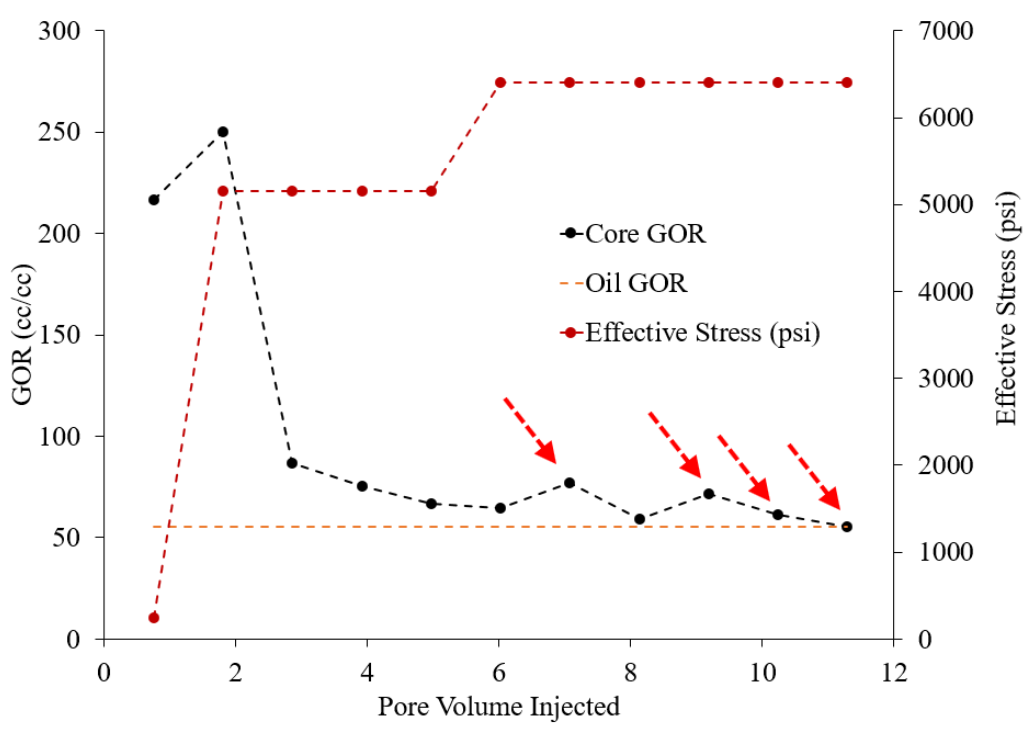

Figure 5: The temporal GOR profiles during live oil injection into the shale core during experiment EOR-1. The effective stress (red dotted curve) was adjusted by increasing the confining pressure. Four inject-soak-inject periods were performed (as highlighted by red arrows). The uncertainty in GOR measurements in this figure is approximately $\pm 1 \%$ of the reported values.

The live oil was injected through the top of the core for 5-10 seconds under a constant pressure of 8000 psi. A fracture was formed creating a high permeability path between the top and bottom of the shale core. Note that because no proppant was used in our experiment, the fracture is highly sensitive to the effective stress imposed on it. Figure 6-a depicts the inlet, outlet, and confining pressure profiles during the fracking 
stage. The fracking stage, as seen in this figure, consisted of: applying a pressure of 8000 psi (At point A in Fig. 6a), a slight pressure drop at the inlet at point (B), which can indicate crack formation, followed by a rise in pressure due to the injection pump compensating for this pressure drop, an abrupt pressure drop as a result of fracture formation at point $(\mathrm{C})$. This is associated with a pressure response at the outlet (point G in Fig 6a). Note that the outlet pressure is connected to a BPR and the fluid accumulated at the outlet was allowed to flow out of the system to keep the pressure constant. The pressure at which fracking ended is at point (D). After 9 seconds of imposing high pressure starting at the inlet at point (E), a leak from injection fluid to confining chamber took place, leading to an increase in the confining pressure starting at point $(\mathrm{H})$. The leak ceased at the inlet and confining pressures of 4950 and 4720 psi, respectively. At point $(\mathrm{F})$ the confining pressure remained at 4700 psi while the inlet pressure dropped gradually to pressures below the confining pressure due to the fluid flow from the inlet to outlet. The small plot inside Figure 6-a shows the longer-term pressure profiles once the fracture was formed. The inlet pressure was adjusted to 4000 psi below the confining pressure to examine the sealing integrity, which verified that there was no leak from the confining fluid into the core inlet. Note that the leak from the inlet to the confining fluid during fracking would not adversely affect the experiment, as it does not contaminate the pore fluid. Figure 6-b exhibits the effective stress compared to the calculated tensile strength of the core. To estimate the tensile strength, we employed the approach described by Emmerich ${ }^{61}$ together with the fracture toughness magnitudes reported by Chandler et al. for the Haynesville shale ${ }^{62}$. Note that the reported fracture toughness is for divider-type fracturing while the fracking performed in this study was the short-transverse mode fracturing, which generally has lower fracture toughness. Thus, the calculated tensile strength would correspond to the upper limit of the fracking stress. Noted that the imposed fracking stress was well above the tensile strength to overcome dynamic effects such as changes in tensile behaviour as the fracture grows from end-tip of quasi-wellbore to the bottom of the sample. The imposed stress is estimated to be greater than twice the tensile strength to ensure creation of the fracture.

The core permeability was measured after fracking to verify the formation of the fracture within the core (see Figure 7). The core permeability was measured by injection of live oil under variable effective stress. The core permeability was relatively high under low stress and decreased significantly as the effective stress increased. At an effective stress of $250 \mathrm{psi}$, the core matrix permeability was $3.94 \times 10^{-4}$ $\mathrm{mD}$ increasing to $0.126 \mathrm{mD}$ after fracking. Under an effective stress of $6650 \mathrm{psi}$, however, the matrix permeability was $8.76 \times 10^{-5} \mathrm{mD}$, which increased to $2.59 \times 10^{-4} \mathrm{mD}$ after fracking. Figure 8 shows photographic images of the core before and after fracking. Fracking led to creation of a single fracture in the middle of the core, which followed the trace of its quasi-wellbore. 


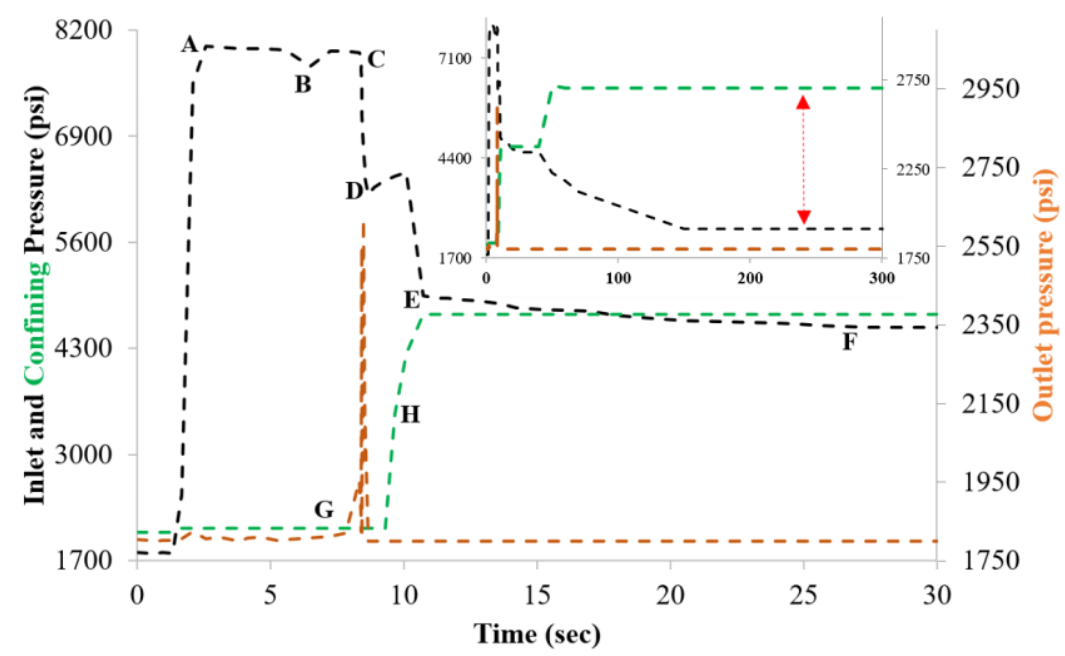

(a)

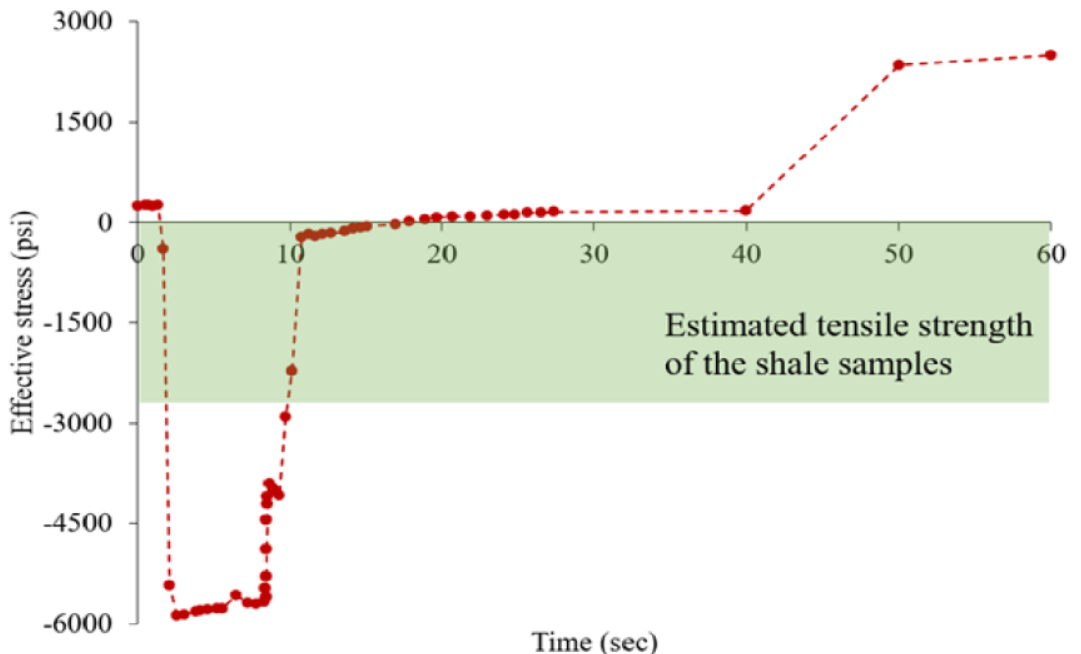

(b)

Figure 6: Profiles of inlet, confining, and outlet pressures during fracking (a) during the first 30 seconds of fracking focusing on detailed pressure changes - see text. The inset plot in (a) illustrates the pressure profiled over the first 5 minutes, demonstrating the core jacket sealing between confining and inlet pressure once the fracture was formed. Red double arrow in the inset indicates the higher confining pressure. (b) Temporal profile of effective stress, i.e. the inlet pressure minus the confining pressure, compared to the estimated tensile strength of the core sample, which verifies fracture formation as the imposed effective stress was significantly higher than tensile stress. On figure (a): (A) fracking started, (B) the pressure drop indicating a crack formation, (C) an abrupt pressure drop resulting from fracture formation, (D) fracking complete, (E) a leak from injection fluid to confining chamber, (F) gradually flow of fracking fluid flow through the fracture, $(\mathrm{G})$ pressure variations at outlet due to fracture formation, $(\mathrm{H})$ The leak from core inlet to confining chamber increased the confining pressure. 


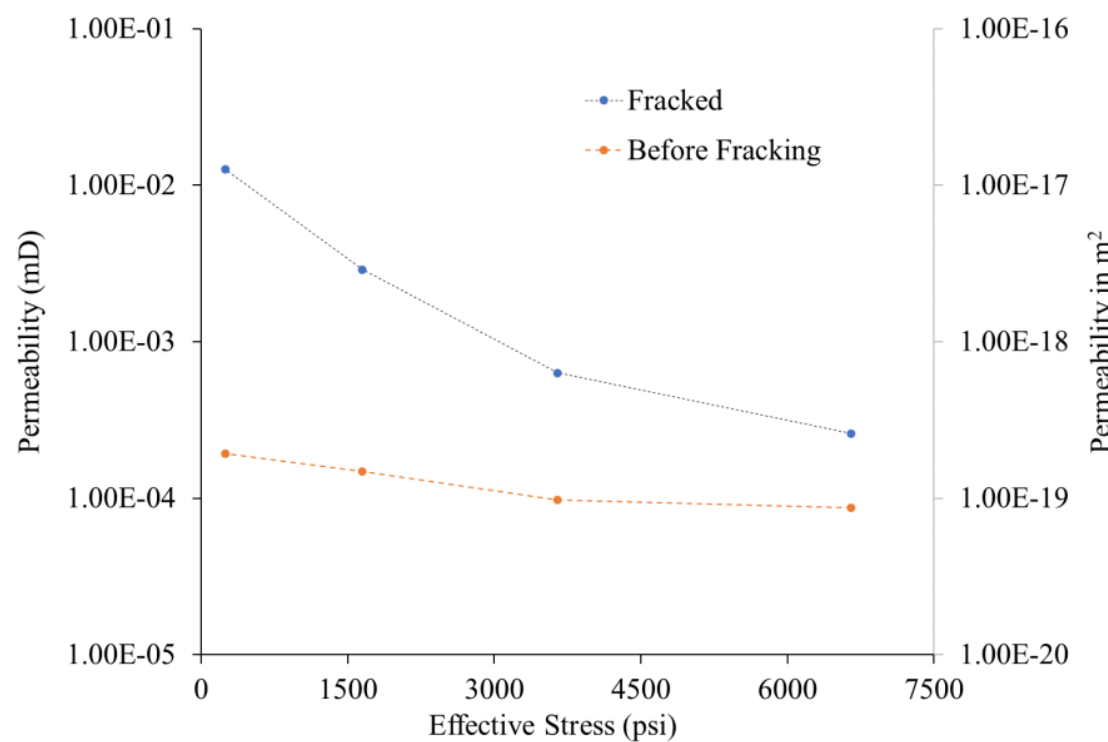

Figure 7: A semi-logarithmic plot of permeability versus effective stress of the core used in experiment EOR-1 before and after fracking. The permeability of the core increased by more than two orders of magnitude upon fracking. The permeability was also highly sensitive to effective stress. Deviations from a linear trend are due to the role of micro-fractures on the permeability of the shale core. The estimated accuracy of the permeability measurements is $\pm 2 \%$. The permeability of the intact core was measured using helium, whereas that of the fracked core was measured using live oil. In both cases, steady state Darcy law was applied.
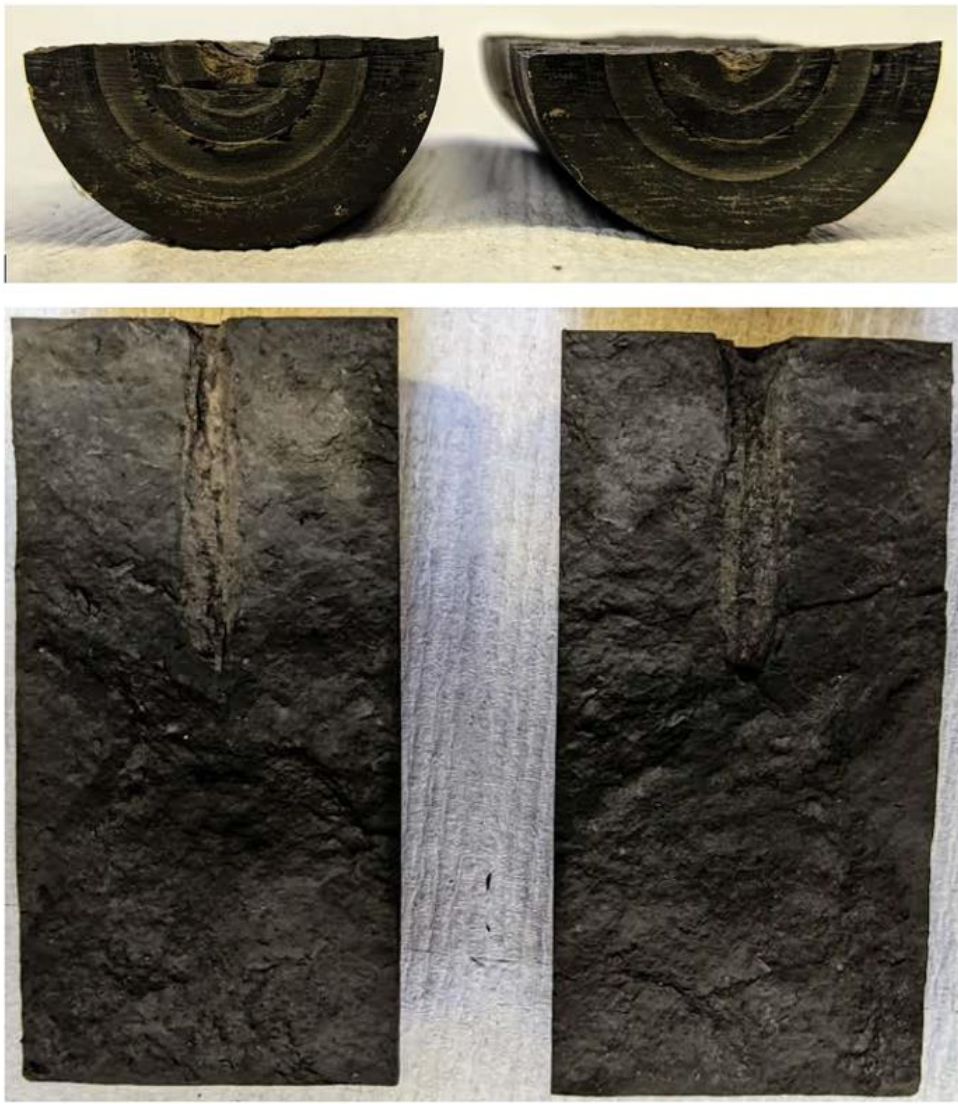

(a)

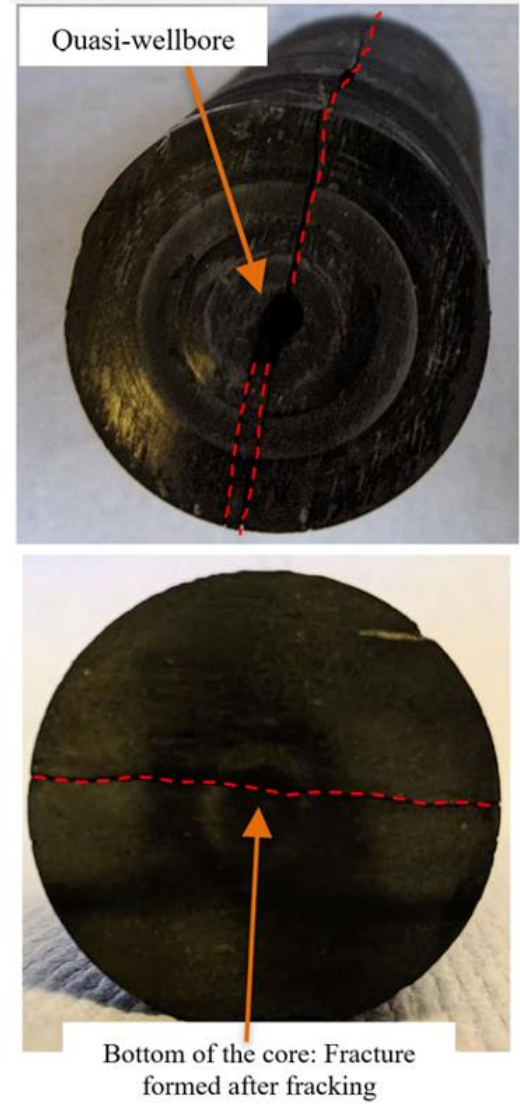

(b)

Figure 8: Photographic images of the shale core used in experiment EOR-1 (a) side and lateral views of the fracked two pieces of the core after the experiment, (b) top and bottom view of the core after the experiment. The lab-scale fracking experiment created a single visible fracture from the top to the bottom of the core. Note also that the color of the core is noticeably darker after the experiment, indicating the invasion of the oil into the core. The dashed lines on image (b) highlight the trace of the 
fractures formed during the in-situ fracking experiment. For an image of the intact core before the fracking experiment, refer to Figure 4-e.

After fracking and measuring the core permeability, seven cycles of huff-n-puff gas injection were performed to evaluate any additional oil recovery. The gas was injected at a pressure of 8000 psi for 5 minutes and then the gas source was disconnected, allowing the injected gas to soak for 18 hours. After the pressure drawdown and fluid production stages, the gas was injected under low effective stress to recover any oil remaining in the tubing and dead volumes. Elimination of the oil in dead volumes is crucial to minimize the adverse impact of this uncertainty. This oil was removed by first injecting the gas through the bypass (see Figure 1) to recover the oil in tubing. Second, the gas was injected into the core under an effective stress of $100 \mathrm{psi}$, at which the fracture is the predominant flow path, to displace the oil remaining in both lines and fracture. Approximately $11 \mathrm{ml}$ of oil was collected by injecting $20 \mathrm{ml}$ of gas at high pressure from this effort.

Figure 9 exhibits the profiles of incremental (Figure 9-a) and cumulative (Figure 9-b) oil recovery for experiment EOR-1. The first three huff-n-puff cycles show the highest oil recovery factors; the last three huff-n-puff cycles exhibited similar oil recoveries. In-situ gas expansion is the likely reason for the measured additional oil recovery, as any gas dissolved in the oil during the injection period will make the oil supersaturated during the depressurization stage. Thus, the excess dissolved gas in the oil would be exsolved as the core was depressurized. Gas expansion has a high impact on oil recovery as the gas tends to remain immobile up to gas saturations of $10 \%$ when it forms in-situ ${ }^{39,63}$. During the first three cycles, the oil in the matrix close to the fracture was recovered efficiently as the gas phase invaded the pores near the fracture because of pressurization. On the other hand, during the last three cycles, the gas is formed inside the matrix deeper away from the fracture at a slower rate due to the limits of slower diffusive transport. So, although injected gas diffusion facilitates enhanced oil recovery during huff-n-puff, the large portion of the additional oil recovery through the EOR process was achieved in the early huff-n-puff cycles where the gas was pressurized into the rock mass closer to the fracture. In terms of cumulative oil recovery, $48 \%$ of additional oil recovery was observed, which indicates the significant potential of gas injection for EOR in liquid-rich shale formations. The oil recovery profiles in the individual huff-n-puff cycles demonstrate that oil recovery is efficient during the early cycles, whereas the profiles show more gradual oil recoveries during the later stages. During the early stages, the oil in the vicinity of the fracture was pushed out by the expansion of the pressurized gas. In the later stages, however, the oil located relatively far away from the fracture was recovered as the oil flow rate is affected by the oil permeability and thus a more gradual oil recovery is observed. During the later cycles, as the oil produced in the early cycles was replaced by invaded gas phase close to the fracture, the oil relative permeability was adversely affected 
413 by the high gas saturation regions of the rock matrix close to the fracture. Although away from the fracture, 414 the oil was produced via the release of the gas previously dissolved in the oil, the oil flow rate was 415 primarily controlled by the relative permeability variations in the face of fracture with the matrix. It thus 416 appears that the EOR efficiency for huff-n-puff processes is primarily controlled by the extent of gas 417 invasion, which can be boosted by lowering the oil-gas IFT and increasing the diffusion coefficient. This 418 can be achieved by using either gases with higher solubility in oil or co-solvent additives in associated 419 gas. Based on our interpretation, the role of micro-fractures and their behavior under the EOR stress 420 regime can be crucial in gas transport. This interpretation is in agreement with the results of pilot studies 421 where it has been attempted to facilitate the penetration of an injected gas ${ }^{7}$.

422 Figure 10 compares the volume of the injected gas against that produced during each cycle. The oil 423 solution gas was subtracted from the total recovered gas volume to discriminate the gas behavior. The 424 difference between injected gas and produced gas indicates the gas volume remaining in the core. The gas 425 volume remaining during the early cycles decreased over time. This is likely due to the decrease in the 426 mass of gas dissolving into the oil remaining in the core over time. On the other hand, the gas volume 427 remaining in the core was approximately similar during each of the last three cycles. As the gas penetration 428 by pressurization is insignificant during the last three cycles, it seems likely that the dominant mechanism 429 of EOR during these last cycles is the diffusive flow of the injected gas into the remaining oil. These 430 observations can be useful for cases where the gas storage is important as well as EOR, e.g. $\mathrm{CO}_{2}$ storage 431 in underground storage reservoirs ${ }^{3}$. These results suggest that the gas storage capacity of the shale matrices 432 would be diminished after the fourth huff-n-puff cycle.

433 The transient pressure decay profiles during the soaking period can help illuminate the diffusion and 434 gas penetration mechanisms. Figure 11 presents the pressure decay profiles during the various huff-n-puff 435 cycles. The profiles, reported as the measured pressure divided by the initial 8000 psi injection pressure, 436 show a larger decline between the first and second cycles. There is a link between Figure 10 and Figure 437 11, where the pressure drop during the soaking period is proportional to the gas phase penetration in the 438 matrix. The pressure decay profiles also indicate that the soaking time was sufficient for the oil and gas to 439 reach steady-state conditions after approximately 17 hours. From the pressure response, however, it can 440 be interpreted that 18 hours of soaking can provide information on gas penetration due to pressurization 441 and diffusion in the huff-n-puff cycles. Analytical and numerical analyses of the pressure profiles permit 442 the calculation of the gas diffusion coefficients. Note that the diffusion process is continuous; it continues 443 until the oil in the matrix becomes fully saturated with the gas and hence, infinite soaking time leads to 444 the oil becoming saturated with the injected gas. 


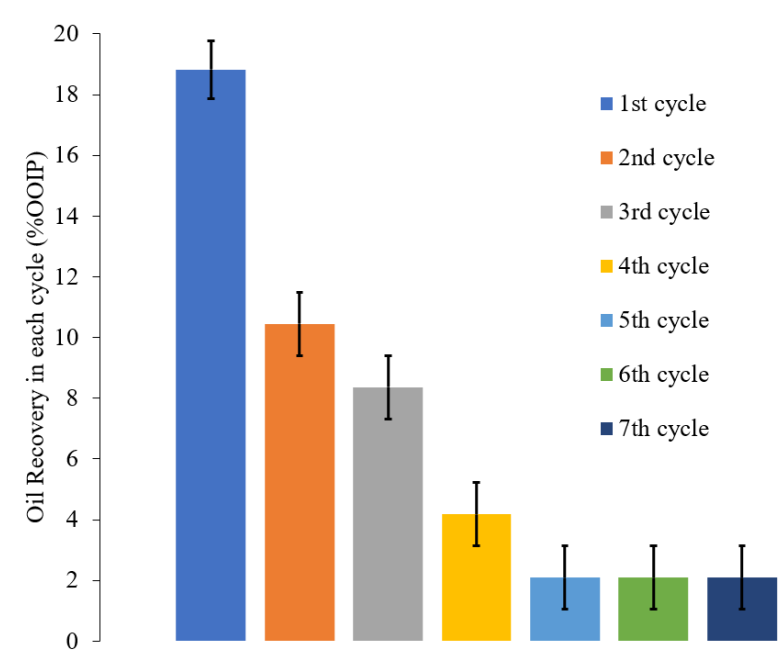

(a)

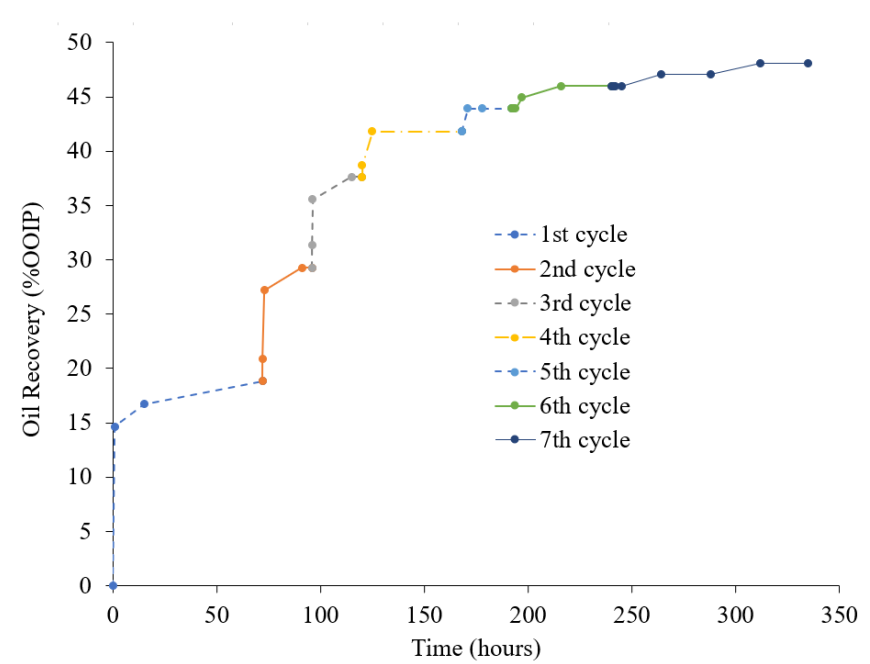

(b)

Figure 9: Results from experiment EOR-1: (a) oil recovery factors as the percentage of original oil in place during each gas huff-n-puff cycle, and (b) cumulative oil recovery versus time.

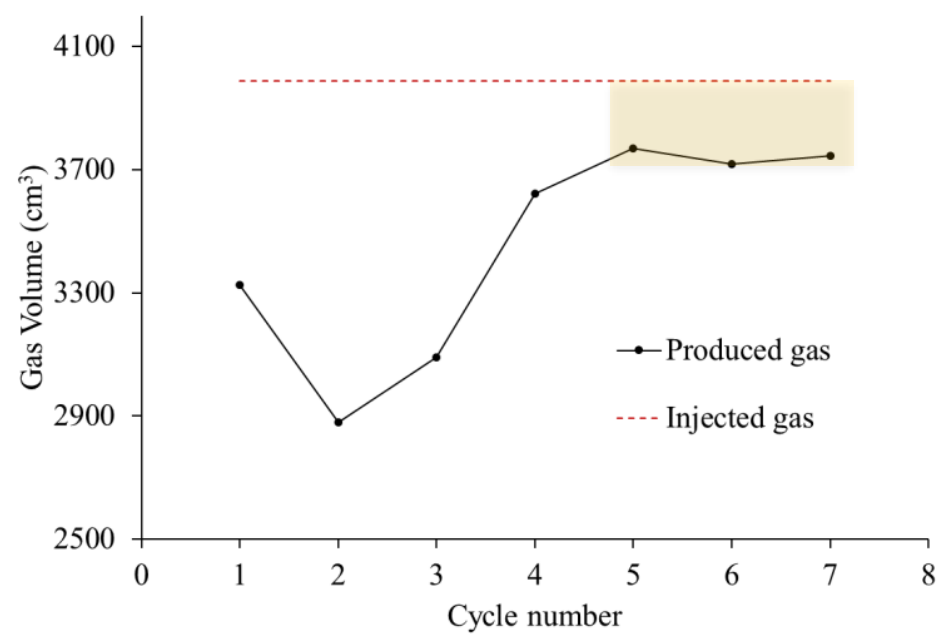

Figure 10: The gas volume produced during each huff-n-puff cycle (in black) compared to that of the injected gas (in red) in experiment EOR-1. The difference between red and black curves is equal to the gas remaining in the core at the end of each huff-n-puff cycle. The yellow rectangle indicates the cycles during which the gas transport is controlled predominantly by diffusion.

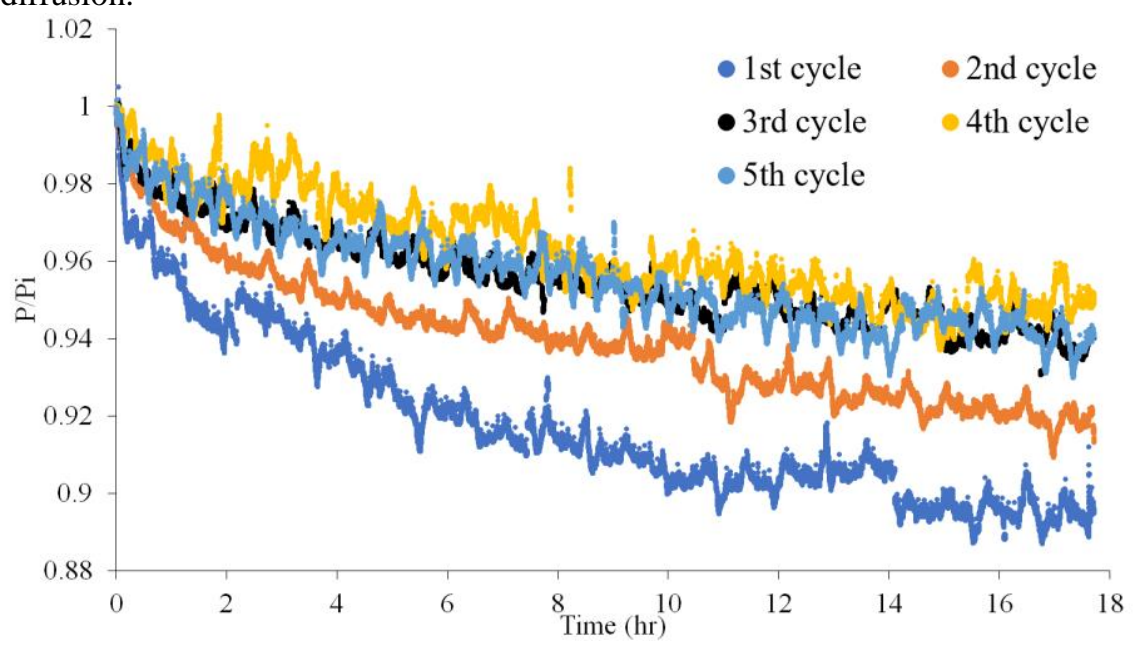

Figure 11: Temporal profiles of the pressure decay for experiment EOR-1 during each soaking period. Because the pressure decay profiles of cycles 6 and 7 are very similar to that of cycle 5, they are not plotted for clarity. 
After the 7 huff-n-puff cycles were complete, a continuous gas injection was performed to investigate the direct displacement of the oil. This injection was performed under an effective stress of 6650 psi, where the fracture permeability is close to the matrix permeability and hence, the oil recovery can be attributed to the displacement type of injection. The gas phase was injected under constant pressure. Figure 12 illustrates the oil recovery profile for this displacement experiment. As the first 0.5 pore volume of gas was injected, no oil recovery was observed, and the effluent was composed of only gas. However, after 0.5 pore volumes of gas were injected, oil recovery was detected. The cumulative oil recovery plateaued at $6.5 \%$ of the original oil in place after 3.2 pore volume injection. The lack of oil recovery at the beginning of the gas injection may be linked to the preference of the gas to penetrate the micro-fractures where gas clusters remained from the preceding huff-n-puff cycles. The rate of the oil recovery does not resemble the normal piston-type displacement observed before the breakthrough during routine coreflood experiments $^{64}$, which implies an effective vaporization mechanism ${ }^{65}$ This demonstrates that the performance of micro-fractures in the rock can be crucial to the oil displacement efficiency. Displacement of the oil after huff-n-puff may not be efficient because micro-fractures in the shale formation would be occupied by the gas from preceding huff-n-puff cycles.

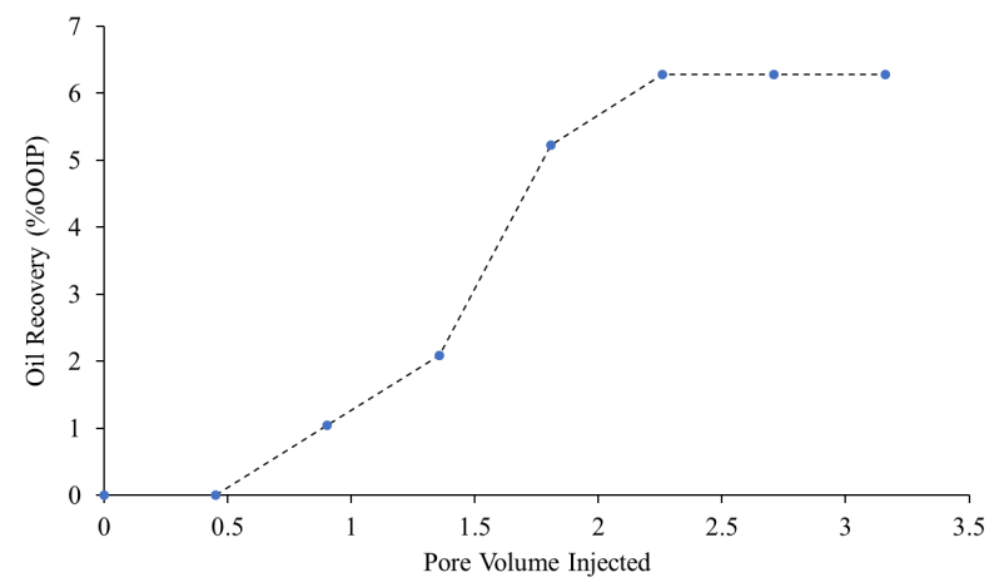

Figure 12: Profile of oil recovery during the displacement stage of experiment EOR-1 under high effective stress. Only 6.5\% of the original oil was produced by gas injection after huff-n-puff.

\subsubsection{Results of experiment EOR-2: Enhanced recovery of dead oil}

The core used in the second experiment, i.e. the Core-2 sample in Table 1, was taken adjacent to the Core- 1 from the same rock sample. In the EOR-2 experiment, no helium pressurization was employed as dead crude oil was used. The core was drilled with similar dimensions as that used in experiment EOR-1. After saturating the core with dead crude oil, the core was fracked. The fracking stage was performed under identical effective stress conditions as in experiment EOR-1. Unlike EOR-1, however, the permeability of the EOR-2 system was measured at only one effective stress, 250 psi. The measured 
permeability of the medium was $0.062 \mathrm{mD}$ after fracking, which is significantly higher than that of the un-fracked core as reported in Table 1.

485 Seven gas huff-n-puff cycles were performed under the same pressure regime in experiment EOR-1. 486 Figure 13 illustrates the incremental and cumulative oil recovery profiles obtained during experiment 487 EOR-2. The incremental oil recovery profile indicates that the first two cycles were efficient, but the 488 subsequent cycles recovered substantially less oil. The cumulative oil recovery of EOR-2 was $33 \%$ of the 489 original oil in place.

$490 \quad$ Figure 14 compares the injected gas against the produced gas after each huff-n-puff cycle. The first 491 two cycles demonstrated distinct behavior compared to the subsequent cycles. Also, the last three cycles 492 show a similar degree of gas volume remaining in the rock. This behavior is likely due to a similar 493 diffusive transport of gas into the remaining oil during the later cycles whereas, in the early cycles, 494 pressurization of the gas leads to a considerable amount of this gas being trapped in the oil near the 495 fracture. During the soaking periods, the pressure decay profiles were measured, which provides insight 496 into gas penetration processes. Figure 15 illustrates the pressure decay profiles obtained during the soaking 497 periods of experiment EOR-2. The first cycle exhibits a high level of gas transport into the shale, which can be attributed to the high gas dissolution capacity of the dead oil. The subsequent cycles behaved differently in response to the pressure drop, which implies that diffusion dominates over pressurization gas penetration during these cycles. This observation suggests that gas huff-n-puff is more efficient for the cycles where gas penetrates into the matrix by pressurization. Specifically, the success of EOR is enhanced by the effectiveness of gas transport into the matrix, which is consistent with field observations.

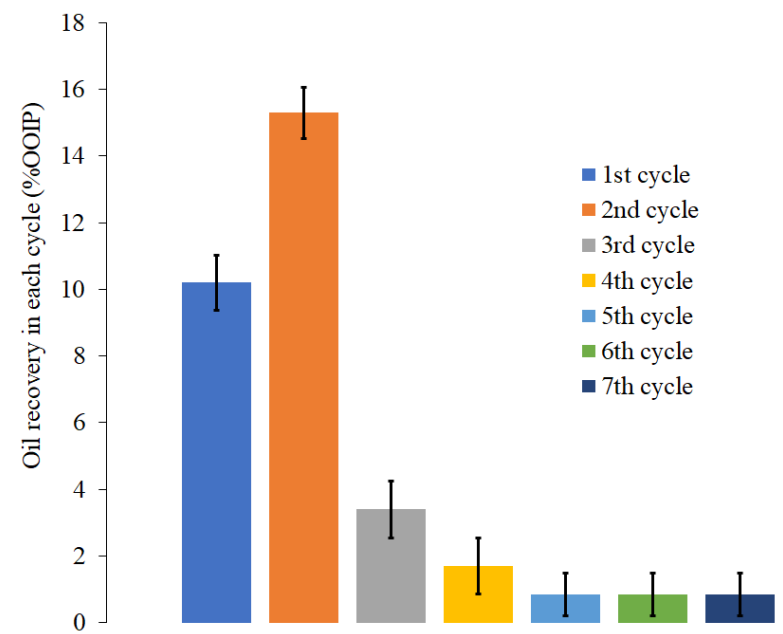

(a)

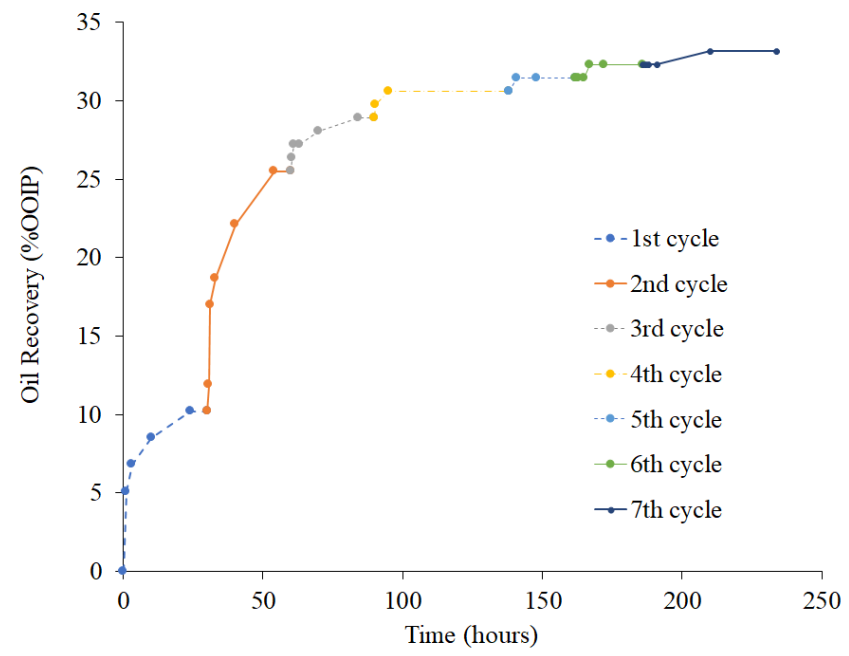

(b)

Figure 13: (a) Oil recovery factor as the percentage of original oil in place in each gas huff-n-puff cycle and (b) cumulative oil recovery versus time during experiment EOR-2. 


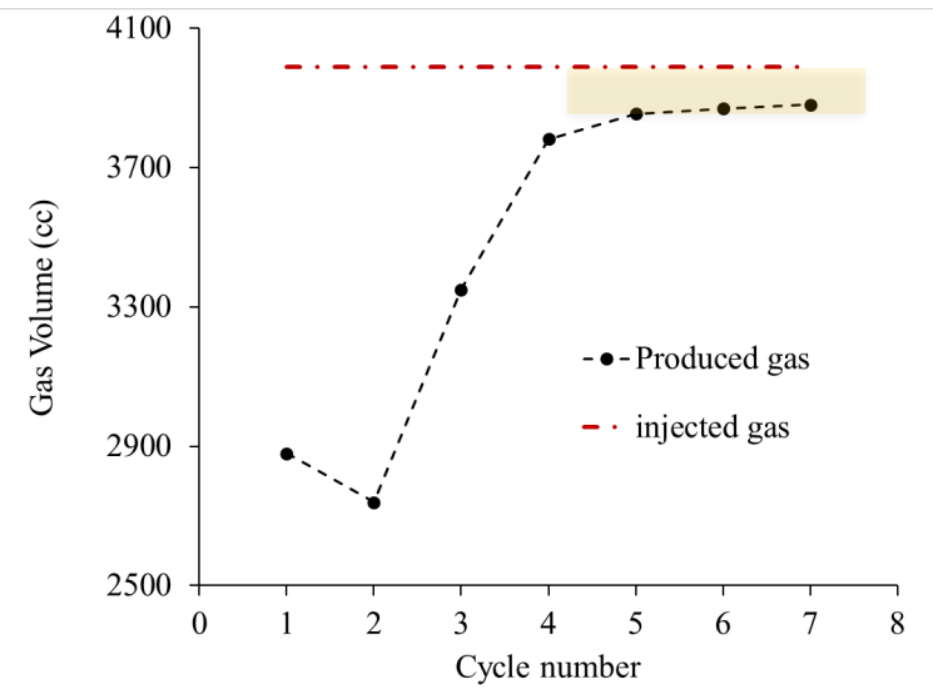

Figure 14: Gas volume collected at each huff-n-puff cycle (in black) compared to the injected gas volume (in red). The yellow rectangle indicates the periods of gas transport controlled predominantly by diffusion.

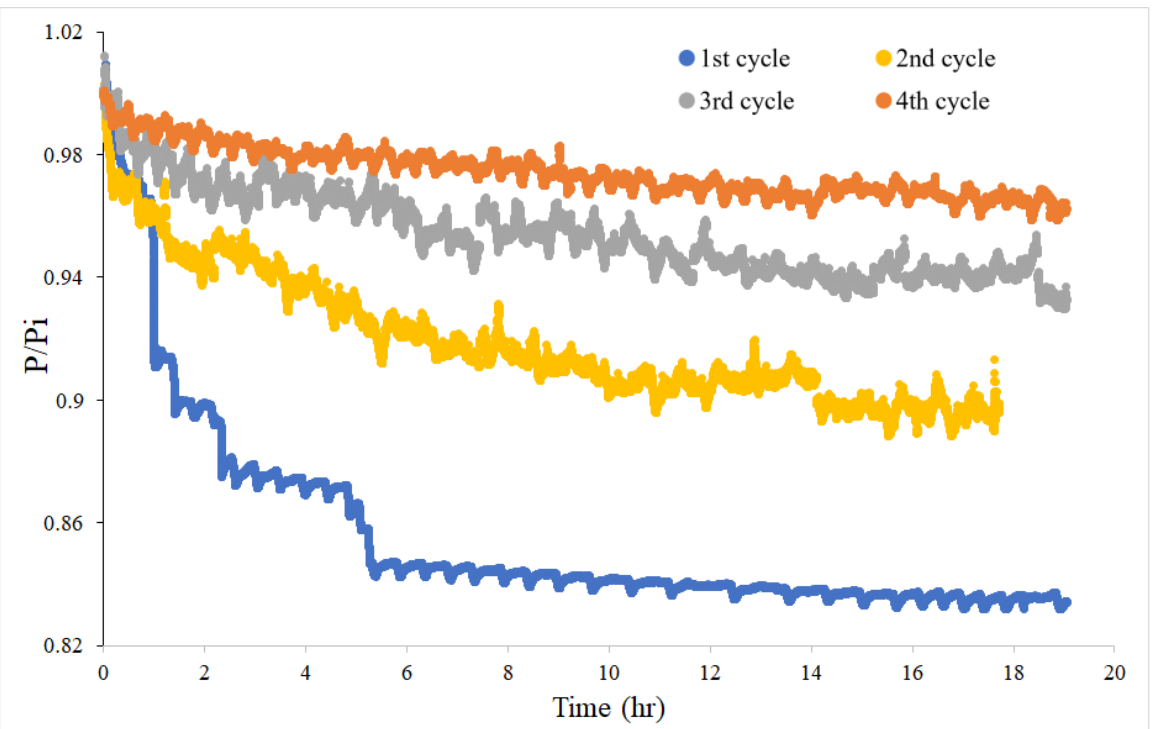

Figure 15: Profiles of the transient pressure decay for the first four soaking periods of experiment EOR-2. Because the pressure decay profiles of cycle 5,6 , and 7 are very similar to that of cycle 4 , they are not plotted for clarity.

\subsubsection{Comparison of live and dead oil experiments}

In addition to providing more realistic laboratory-scale evaluations of EOR strategies, one of the advantages of the new laboratory methodology presented here is the ability to reveal the role of solution gas of the oil. Unlike dead oils, live oils contain a substantial amount of solution gases. Performing huffn-puff experiments for the oil at bubble point pressure leads to the liberation of the dissolved gas during depressurization. In contrast, the dead oil has a higher affinity to dissolve the injected gas, but the gas has a lower diffusion coefficient through the dead oil because of its higher viscosity compared to live oil. Also, the interfacial tension (IFT) between the oil and gas is reduced as solution gas content is increased. IFT plays an important role on the gas dissolution kinetics into the oil. Therefore, several competing 
524 parameters can impact the outcome of huff-n-puff cycles. Nevertheless, a comparison of the results of live oil and dead oil can help illuminate the relative importance of the fluid and rock properties.

Figure 16 compares the incremental oil recovery for the two experiments performed in this study. First, note the mechanistic difference in the behavior of the cycles; incremental recovery from the live oil experiment has a monotonically decreasing trend, whereas incremental recovery from the dead oil experiment increased from cycle 1 to cycle 2 and then dropped. Second, oil recovery from the dead oil experiment was substantially lower from the third cycle onward, but the live oil exhibited a more gradual decline trend leading to a significant drop in recovery only after the fourth cycle. Overall, therefore, a noticeable difference is seen in the behavior of the live compared to the dead oil EOR during the first three cycles of the huff-n-puff. It follows that using dead oil in such experiments may not capture the underlying mechanisms behind EOR in subsurface live oil systems. In both experiments, the amount of the oil recovery is similar during the last three cycles indicating that the oil recovery mechanisms are similar during these cycles. Oil recovery during the later cycles is primarily controlled by diffusion of gas into the oil and oil-gas relative permeabilities. Three main mechanisms of pressurization, dissolution, and diffusion are in play for gas transport and oil recovery. The relative role of these mechanisms varies depending on distance from the fracture. Hence, numerical simulation and upscaling of the results can be challenging. Preliminary calculations indicate an approximately $0.15 \mathrm{~cm}$ of gas penetration from the fracture into the matrix during each huff-n-puff cycle.

Figure 17 compares the cumulative oil recovery measured during the experiments. After 7 huff-n-puff cycles, $48 \%$ of additional recovery was achieved for the live oils, whereas only $33 \%$ additional oil recovery was observed for the dead oils. In addition, oil recovery in the live oil experiment occurred faster; as much additional oil was recovered after two huff-n-puff cycles during the live oil experiment as recovered after three cycles during the dead oil experiment. Furthermore, the live oil recovery profiles for each cycle has a sharper trend compared to the gradual oil recovery in the dead oil.

Figure 18 compares the results of injected and produced gas volumes for the two experiments. Firstly, the remaining gas volume was higher for the dead oil experiment during the first two cycles. However, the trend reverses from the third cycle onward. During the early cycles, the gas pressurized into the matrix is dissolved rapidly into the dead oil. As more huff-n-puff cycles were performed, diffusion becomes the dominant gas transport mechanism, which is more pronounced in the live oil as it has a higher diffusion coefficient. This higher diffusion for the live oil is also evident in the gas profiles for the last three cycles, as the remaining gas was higher in the live oil system.

The laboratory approach developed in this study irreversibly alters the core by inducing a permanent 
laboratory experiments performed on shale oil cores. As the cores were obtained from natural subsurface formations, it is conceivable that heterogeneities in core properties may have affected the results described above. This may lead to uncertainties when comparing results obtained from the two cores. Although some of the differences observed between the two experiments can be attributed to heterogeneities, the results demonstrate significant differences in the fundamental behavior of the live compared to dead oils. Notably substantial differences were observed in the oil recovery and gas storage capacities of the live compared to the dead oil experiments. Such differences are larger than those that could be attributed to heterogeneities in shales; shale heterogeneity has been reported to possibly introduce only 4-6\% differences in oil recovery during huff-n-puff efforts ${ }^{66}$. Therefore, the differences in the oil recovery and gas storage behaviors of the live versus the dead oil observed in this study are likely robust and illustrate the effect of the presence of the solution gas content of the oils on EOR efficiency by huff-n-puff.

Another implication of the results presented in this study concerns $\mathrm{CO}_{2}$ storage. The $\mathrm{CO}_{2}$ storage capacity of shale oil formations can be significant ${ }^{40,66-69}$. Based on Figure 18, the amount of gas that remains in the shale matrix can be increased by more than $10 \%$ when live oil was used rather than dead oil, although the dead oil has much higher intrinsic capacity to store the gas in a dissolved form. Our results suggest that the improved gas transport in the live oil system could lead to enhanced gas trapping in the live oil ${ }^{70,71}$. The results also suggest that gas dissolution is not instantaneous in the nano-pores, where mixing between oil and gas is hindered, and therefore does not facilitate gas dissolution. Furthermore, the results of the dead oil experiment may not be readily re-scaled for live oils by modifying the dissolution capacity. As a consequence, it would be misleading to consider the results of dead oil tests to assess the $\mathrm{CO}_{2}$ storage capacity of live oil formations.

Live crude oil

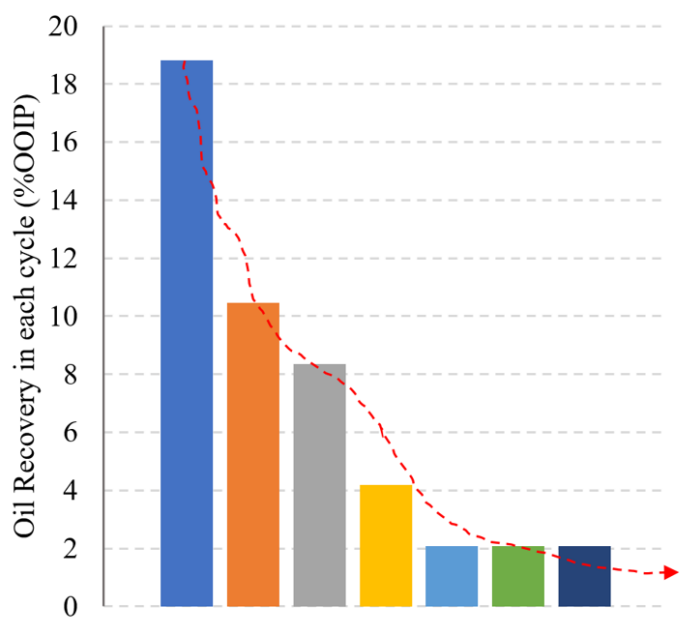

Dead crude oil

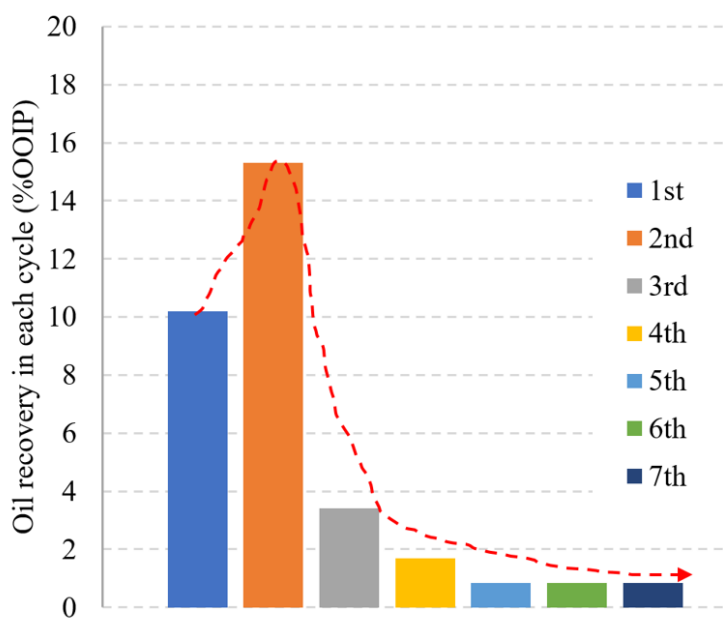

Figure 16: Incremental oil recovery factor for experiment EOR-1 (live oil) and experiment EOR-2 (dead oil) for each huff-npuff cycle. In contrast to the live oil experiment, the dead oil experiment has a non-monotonic decreasing trend. Also, after the second cycle, the dead oil experiment exhibits a sharp drop in oil recovery. Both plots share the same legend on the right side of the figure. 


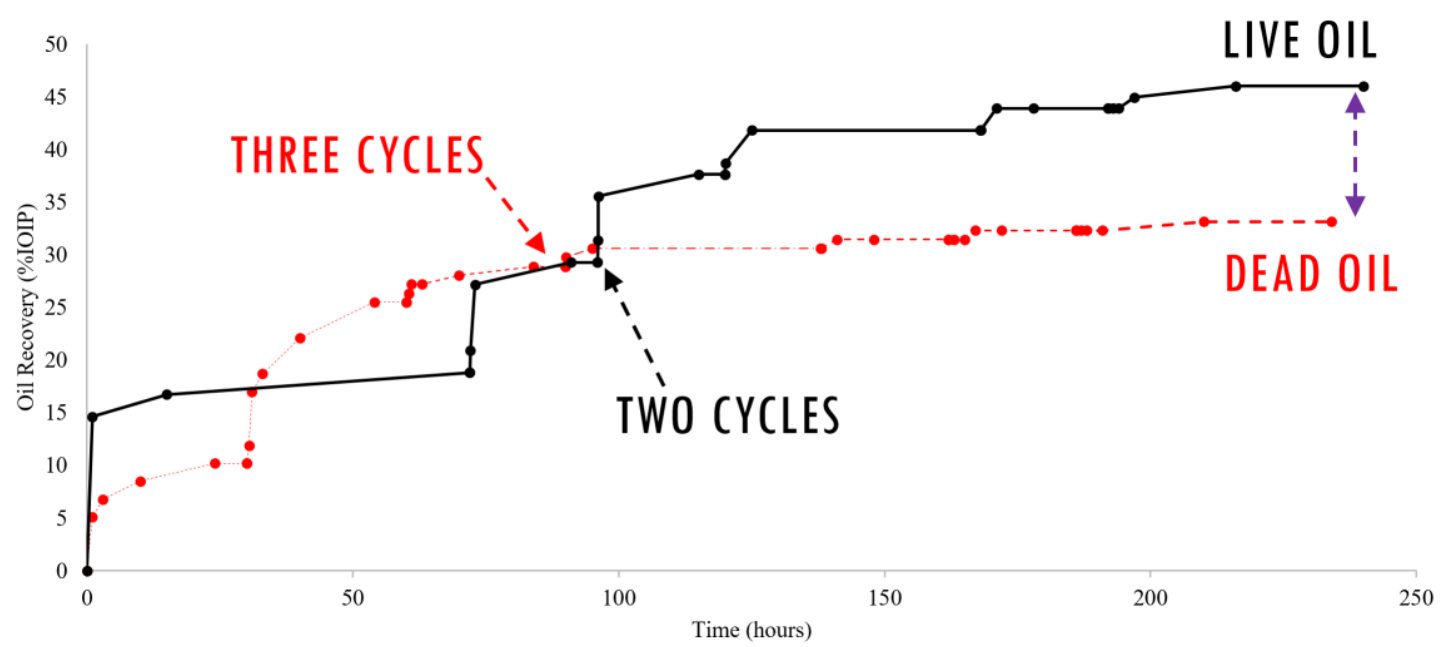

Figure 17: Cumulative oil recovery factor for experiment EOR-1 (live oil) and experiment EOR-2 (dead oil). Two huff-n-puff cycles in the live oil experiment generate as much additional recovery as three cycles during the dead oil experiment. The purple arrow highlights the overall recovery difference after 7 huff-n-puff cycles i.e. $15.1 \%$ of the original oil.

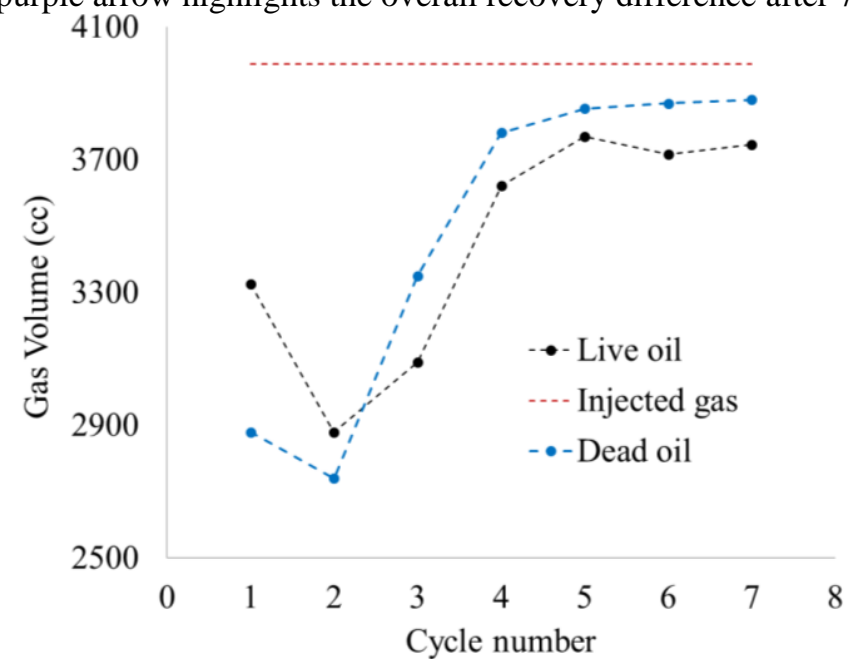

Figure 18: Produced and injected gas volumes during experiments EOR-1 and EOR-2. During the early cycles, the higher gas solubility of the dead oil leads to more gas remaining in the core after each cycle compared to the live oil experiment. The more rapid diffusive gas transport within the live oil leads to more gas being retained during the later cycles. The uncertainty in the measurements is smaller than the symbol size.

\section{Conclusions}

The majority of EOR studies in shale oil reservoirs performed in the past were limited to simplified cases where dead oil was used, or the core was over-exposed to the huff-n-puff fluids. In this study, a new experimental methodology was developed for studying enhanced oil recovery and gas storage capacity in liquid-rich shales. This new method enables performing experiments at more realistic reservoir conditions. Specifically, the coreflood apparatus was modified to permit injection pressures considerably above the confining pressures. This adaptation allows the creation of fractures within the shale in-situ. The use of shale samples cored along their sedimentary bedding direction in this apparatus leads to the formation of a single fracture from the inlet to the outlet. 
enhanced oil recovery was achieved from the shale core saturated with live oil, whereas only $33 \%$ of EOR was achieved from the shale core saturated with dead oil. It was observed that the oil recovery during each huff-n-puff cycle has a monotonic declining trend in the live oil system. This is consistent with field performance and shows the importance of applying EOR technology early after well completion. Field studies have shown that normally just a few huff-n-puff cycles are optimal. Using dead oil, the incremental oil recovery increases during the early huff-n-puff cycles and then it decreases notably. In-situ gas formation can influence strongly the efficiency of huff-n-puff highlighting the importance of taking account realistic reservoir conditions during such experiments. It could be inferred that the pressurization mechanism is more effective than diffusion and hence, improving gas penetration by reducing oil-gas interfacial tension can be helpful for enhanced oil recovery. Overall, the results of this study demonstrate that conventional experimental approaches using dead crude oils may misrepresent substantially the EOR and gas storage potentials in shale and tight oil reservoirs. It can be inferred that up-scaling the lab results to field scales requires detailed analyses of pressurization, dissolution, and diffusion mechanisms near and away from the fractures. The gas penetration by pressurization is limited to the near fracture, which controlled the high portion of the oil recovery during the early huff-n-puff cycles.

\section{Acknowledgments}

This work is part of the Science for Clean Energy (S4CE) European research consortium funded by the European Union's Horizon 2020 research and innovation programme under grant agreement No 764810. We thank Neil Hugh for technical support on developing the new apparatus and James Davy for acquiring and interpretation of SEM images. Also, we highly appreciate the fruitful discussions with Donald Westacott from Halliburton. PRS and FI would like to acknowledge the support by EPSRC (EP/N032888/1, EP/K005030/1).

\section{References}

1. S. Joshi, "EOR: Next Frontier for Unconventional Oil" Journal of Petroleum Technology, vol. 66, no. 06, pp. 20-22, 2014.

2. J. Sheng, "Critical review of field EOR projects in shale and tight reservoirs" Journal of Petroleum Science and Engineering, vol. 159, pp. 654-665, 2017.

3. B. Jai, J. Tsau and R. Barati, "A review of the current progress of $\mathrm{CO}_{2}$ injection EOR and carbon storage in shale oil reservoirs" Fuel, vol. 236, pp. 404-427, 2019.

4. J. Ma, X. Wang, R. Gao, F. Zeng, C. Huang, P. Tontiwachwuthkul, Z. Liang, "Enhanced light oil recovery from tight formations through $\mathrm{CO}_{2}$ huff 'n' puff processes”' Fuel, vol. 154, pp. 35-44, 2015.

5. S. Rassenfoss, "Shale EOR Works, But Will It Make a Difference?" Journal of Petroleum Technology, vol. 69, no. 10, p. 01 October 2017, 2017.

6. S. Rassenfoss, "In the Shale Business, It's Time for Another Revolution" Journal of Petroleum Technology, vol. 70, no. 9, p. 23 July 2018, 2018. 
7. A. Katiyar, P. D. Patil, N. Rohilla, P. Rozowski, J. Evans, T. Bozeman and Q. Nguyen, "Industry-first hydrocarbonfoam EOR pilot in an unconventional reservoir: design, implimentation, and performance analysis," in Unconventional Resources Technology Conference, Denver, Colorado, USA, 2019.

8. B. Eftekhari, M. Mardar and T. W. Patzek, "Field data provide estimates of effective permeability, fracture spacing, well drainage area and incremental production in gas shales" Journal of Natural Gas Science and Engineering, vol. 56, pp. 141$151,2018$.

9. R. B. Jackson, A. Vengosh, J. W. Carey, R. J. Davies, T. H. Darrah, F. O'Sullivan and G. Petron, "The environmental costs and benefits of fracking" Annual Review of Environment and Resources, vol. 39, pp. 327-362, 2014.

10. Y. Zee Ma and S. A. Holditch, Unconventional Oil and Gas Resources Handbook: Evaluation and Development, https://doi.org/10.1016/C2014-0-01377-9: Gulf Professional Publishing, 2016.

11. F. Tuero, M. Crotti and I. Labayen, "Water Imbibition EOR Proposal for Shale Oil Scenarios" in SPE Latin America and Caribbean Petroleum Engineering Conference, 17-19 May, Buenos Aires, Argentina, 2017.

12. F. Du and B. Nojabaei, "A Review of Gas Injection in Shale Reservoirs: Enhanced Oil/Gas Recovery Approaches and Greenhouse Gas Control" Energies, vol. 12, p. 2355, 2019.

13. D. Alfarge, M. Wei and B. Bai, "Factors Affecting $\mathrm{CO}_{2}-\mathrm{EOR}$ in Shale-Oil Reservoirs: Numerical Simulation Study and Pilot Tests," Energy and Fuels, vol. 31, pp. 8462-8480, 2017.

14 T. B. Hoffman, "Huff-N-Puff Gas Injection Pilot Projects in the Eagle Ford," in SPE Canada Unconventional Resources Conference, Calgary, Alberta, Canada, 2018.

15. T. B. Hoffman and J. Evans, "Improved Oil Recovery IOR Pilot Projects in the Bakken Formation," Denver, Colorado, USA, 2016.

16. T. B. Hoffman and S. Shoaib, "CO 2 Flooding to Increase Recovery for Unconventional Liquid-rich Reservoirs," Journal of Energy Resources Technology, vol. 136, pp. 022801-1 to 10, 2014.

17. IPCC, " Global Warming of $1.5^{\circ} \mathrm{C}$. An IPCC Special Report on the impacts of global warming of $1.5^{\circ} \mathrm{C}$. , $^{\text {in }}$ Press, Intergovernmental Panel on Climate Change, 2018.

18. J. M. Matter, M. Stute, S. O. Snæbjornsdottir, E. H. Oelkers, S. R. Gislason, E. S. Aradottir, B. Sigfusson, I. Gunnarsson, H. Sigurdardottir, E. Gunnlaugsson, G. Axelsson, H. A. Alfredsson, D. Wolff-Boenisch, K. Mesfin, D. F. Taya, J. Hall, K. Dideriksen and W. S. Broecker, "Rapid carbon mineralization for permanent disposal of anthropogenic carbon dioxide emissions," Science, vol. 352, no. 6291, pp. 1312-1314, 2016.

$$
\text { 19. S. R. Gislason and E. H. Oelkers, "Carbon storage in basalt," Science, vol. 344, no. 6182, pp. 373-374, } 2014 .
$$

20. B. P. V. D. M. e. a. Hmiel, "Preindustrial ${ }^{14} \mathrm{CH}_{4}$ indicates greater anthropogenic fossil $\mathrm{CH}_{4}$ emissions," Nature, vol. 578, p. 409-412, 2020.

21. R. W. Howarth, "Ideas and perspectives: is shale gas a major driver of recent increase in global atmospheric methane?" Biogeosciences, vol. 16, p. 3033-3046, 2019.

22. T. B. Hoffman, S. Sonnenberg, H. Kazemi and Q. Cui, "The Benefits of Reinjecting Instead of Flaring Produced Gas in Unconventional Oil Reservoirs," in Unconventional Resources Technology Conference (URTeC), Denver, Colorado, USA, 2014.

23. L. Jin, J. A. Sorenson, S. B. Hawthorne, S. A. Smith, L. J. Pekot, N. W. Bosshart, M. E. Burton-Kelly, D. J. Miller, C. B. Grabanski, C. D. Gorecki, E. N. Steadman and J. A. Harju, "Improving Oil Recovery by Use of Carbon Dioxide in the Bakken Unconventional System: A Laboratory Investigation," SPE Reservoir Evaluation \& Engineering, vol. 20, no. 03, pp. 602-612, 2017. 
24. L. Jin, S. Hawthorne, J. Sorensen, L. Pekot, B. Kurz, S. Smith, L. Heebink, V. Herdegen, N. Bosshart, J. Torres, C. Dalkhaa, K. Petereson, C. Gorecki, E. Steadman and J. Harju, "Advancing $\mathrm{CO}_{2}$ enhanced oil recovery and storage in unconventional oilplay_Experimental studies on Bakken shales," Applied Energy, vol. 208, pp. 171-183, 2017.

25. L. Lei, C. Wang, D. Li, J. Fu, Y. Su and Y. Lv, "Experimental investigation of shale oil recovery from Qianjiang core samples by the CO2 huff-n-puff EOR method," RSC Advances, vol. 9, pp. 28857-28869, 2019.

26. L. Li, Y. Zhang and J. Sheng, "Effect of the Injection Pressure on Enhancing Oil Recovery in Shale Cores during the CO2 Huff-n-Puff Process When It Is above and below the Minimum Miscibility Pressure," Energy and Fuels, vol. 31 , pp. 38563867, 2017.

27. Y. Sun, Q. Li, D. Yang and X. Liu, "Laboratory core flooding experimental systems for $\mathrm{CO}_{2}$ geosequestration: An updated review over the past decade," Journal of Rock Mechanics and Geotechnical Engineering, vol. 8, pp. 113-126, 2016.

28. Y. Assef and P. P. Almao, "Evaluation of Cyclic Gas Injection in Enhanced Recovery from Unconventional Light Oil Reservoirs: Effect of Gas Type and Fracture Spacing," Energies, vol. 12, no. 7, p. 1370, 2019.

29. K. Joslin, A. Abraham, T. Thaker, V. Pathak and A. Kumar, "Viability of EOR Processes in the Bakken Under Geological and Economic Uncertainty," in SPE Canada Unconventional Resources Conference, Calgary, Alberta, Canada, 2018.

30. S. Malo, J. McNamara, N. Volkmer and E. Amirian, "Eagle Ford - Introducing the Big Bad Wolf," in SPE/AAPG/SEG Unconventional Resources Technology Conference, Denver, Colorado, USA, 2019.

31. T. Jacobs, "Shale EOR Delivers, So Why Won't the Sector Go Big?" Journal of Petroleum Technology, vol. 71, no. 5, pp. 37-41, 2019.

32. T. Gamadi, J. Sheng, M. Soliman, H. Menouar, M. Watson and H. Emadbaladehi, "An Experimental Study of Cyclic $\mathrm{CO}_{2}$ Injection to Improve Shale Oil Recovery," in SPE Improved Oil Recovery Symposium, Tulsa, Oklahoma, USA, 2014.

33. H. Wang, Z. Lun, C. Lv, D. Lang, B. Ji, M. Luo, W. Pan, R. Wang and K. Gong, "Measurement and Visualization of Tight Rock Exposed to $\mathrm{CO}_{2}$ Using NMR Relaxometry and MRI," Scientific Reports, vol. 7, p. 44354, 2017.

34. S. Liu, V. Sahni, J. Tan, D. Beckett and T. Vo, "Laboratory Investigation of EOR Techniques for Organic Rich Shales in the Permian Basin," in Unconventional Resources Technology Conference (URTeC), Houston, Texas, USA, 2018.

35. S. B. Hawthorne, C. D. Gorecki, J. A. Sorensen, D. J. Miller, J. A. Harju and S. L. Melzer, "Hydrocarbon Mobilization Mechanisms Using $\mathrm{CO}_{2}$ in an Unconventional Oil Play," Energy Procedia, vol. 63, pp. 7717-7723, 2014.

36. B. Li, H. Bai, A. Li, L. Zhang and Q. Zhang, "Experimental investigation on influencing factors of $\mathrm{CO}_{2}$ huff puff under fractured low permeability conditions," Energy Science and Engineering, vol. 7, pp. 1621-1631, 2019.

37. J. J. Trivedi and T. Babadaghli, "Experimental and numerical modeling of the mass transfer between rock matrix and fracture," Chemical Engineering Journal, vol. 146, pp. 194-204, 2009.

38. H. Karimaie, G. R. Darvish, E. Lindeberg and O. Torsater, "Secondary and tertiary gas injection in fractured carbonate rock: Experimental study," Journal of Petroleum Science and Engineering, vol. 62, pp. 45-51, 2008.

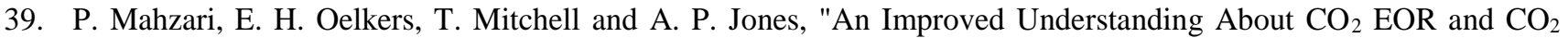
Storage in Liquid-Rich Shale Reservoirs," in SPE Europec featured at 81st EAGE Conference and Exhibition, London, England, UK, 2019.

40. P. Mahzari, A. P. Jones and E. H. Oelkers, "An integrated evaluation of enhanced oil recovery and geochemical processes for carbonated water injection in carbonate rocks," Journal of Petroleum Science and Engineering, vol. 181, p. $106188,2019$.

41. P. Mahzari, T. Mitchell, A. P. Jones and E. H. Oelkers, "A New Mechanism for Enhanced Oil Recovery by $\mathrm{CO}_{2}$ in Shale Oil Reservoirs," in IOR 2019 - 20th European Symposium on Improved Oil Recovery, Pau, France, 2019. 
42. P. Mahzari, A. P. Jones and E. H. Oelkers, "An integrated evaluation of enhanced oil recovery and geochemical processes for carbonated water injection in carbonate rocks," Journal of Petroleum Science and Engineering, vol. 181, p. 106188, 2019.

43. G. R. Darvish, E. G. Lindeberg, T. Holt, J. Kleppe and S. A. Utne, "Reservoir Conditions Laboratory Experiments of CO2 Injection Into Fractured Cores," in SPE/DOE Symposium on Improved Oil Recovery, 22-26 April, Tulsa, Oklahoma, USA, 2006.

44. G. H. Abdul-Majeed and N. A. Al-Soof, "Estimation of gas-oil surface tension," Journal of Petroleum Science and Engineering, vol. 27, pp. 197-200, 2000.

45. T. B. Hoffman and D. Reichhardt, "Quantitative Evaluation of Recovery Mechanisms for Huff-n-puff Gas Injection in Unconventional Reservoirs," in SPE/AAPG/SEG Unconventional Resources Technology Conference, Denver, Colorado, USA, 2019.

46. B. Jia, J. Tsau and R. Barati, "Role of Molecular Diffusion in Heterogeneous Shale Reservoirs During $\mathrm{CO}_{2} \mathrm{Huff}_{-\mathrm{n}}$ puff," in SPE Europec featured at 79th EAGE Conference and Exhibition, 12-15 June, Paris, France, 2017.

47. P. Nguyen, J. W. Carey, H. S. Viswanathan and M. Porter, "Effectiveness of supercritical-CO $\mathrm{CO}_{2}$ and $\mathrm{N}_{2}$ huff-and-puff methods of enhanced oil recovery in shale fracture networks using microfluidic experiments," Applied Energy, vol. 230, pp. $160-174,2018$.

48. H. Sheikha and M. Pooladi-Darvish, "Micro Bubbles in Solution-Gas Drive in Heavy Oil: Their Existence and Importance," Transport in Porous Media, vol. 93, p. 495-516, 2012.

49. E. Rutter and A. Hackston, "On the effective stress law for rock-on-rock frictional sliding, and fault slip triggered by means of fluid injection," Philosophical Transactions A, vol. 375, p. $20160001,2017$.

50. X. Li, Z. Feng, G. Han, D. Elsworth, C. Marone and D. Saffer, "Hydraulic Fracturing in Shale with $\mathrm{H}_{2} \mathrm{O}, \mathrm{CO}_{2}$ and $\mathrm{N}_{2}$," in 49th US Rock Mechanics / Geomechanics Symposium, San Francisco, CA, USA, 2015.

51. N. R. Backeberg, F. Iacoviello, M. Rittner, T. M. Mitchell, A. P. Jones, R. Day, J. Wheeler, P. R. Shearing, P. Vermeesch and A. Striolo, "Quantifying the anisotropy and tortuosity of permeable pathways in clay-rich mudstones using models based on X-ray tomography," Scientific Reports, vol. 7, p. 14838, 2017.

52. S. Gehne, N. D. Forbes Inskip, P. M. Benson, P. G. Meredith and N. Koor, "Fluid-Driven Tensile Fracture and Fracture Toughness in Nash Point Shale at Elevated Pressure," JGR Solid Earth, vol. 125, p. e2019JB018971, 2020.

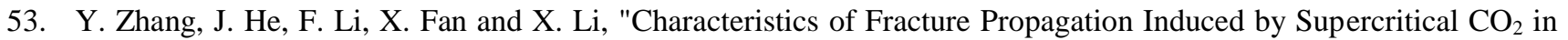
Inter-Salt-Shale Reservoir," Geofluids, vol. Volume 2019, p. 7132843, 2019.

54. J. A. Nunn, "Burial and thermal history of the Haynesville shale: implications for overpressure, gas generation, and natural hydrofracture," GCAGS Journal, vol. 1, pp. 81-96, 2012.

55. M. Apostolopoulou, M. S. Santos, M. Hamza, T. Bui, I. G. Economou, M. Stamatakis and A. Striolo, "Quantifying Pore Width Effects on Diffusivity via a Novel 3D Stochastic Approach with Input from Atomistic Molecular Dynamics Simulations," J. Chem. Theory Comput, vol. 15, pp. 6907-6922, 2019.

56. J. Hwang and R. Pini, "Supercritical CO2 and CH4 Uptake by Illite-Smectite Clay Minerals," Environ. Sci. Technol., vol. 53, pp. 11588-11596, 2019.

57. F. Iacoviello, X. Lu, T. M. Mitchell, D. J. L. Brett and P. R. Shearing, "The Imaging Resolution and Knudsen Efect on the Mass Transport of Shale Gas Assisted by Multi-length Scale X-Ray Computed Tomography," Scientific Report, vol. 9, p. $19465,2019$.

58. S. Basu, J. Ahmed, A. P. Jones and A. B. Verchovsky, "Characterisation of carbon components and their isotopic composition in gas shales," Energy Procedia, vol. 146, pp. 47-52, 2018. 
59. S. Basu, A. B. Verchovsky, A. Bogush, A. P. Jones and A. Jourdan, "Stability of Organic Carbon Components in Shale: Implications for Carbon Cycle," Frontier in Earth Sciences, vol. 7, p. 297, 2019.

60. P. J. Dowey and K. G. Taylor, "Extensive authigenic quartz overgrowths in the gas-bearing Haynesville-Bossier Shale, USA," Sedimentary Geology, vol. 356, pp. 15-25, 2017.

61. F. G. Emmerich, "Tensile strength and fracture toughness of brittle materials," Journal of Applied Physics, vol. 102, p. $073504,2007$.

62. M. R. Chandler, P. G. Meredith, N. Brantut and B. R. Crawford, "Fracture toughness anisotropy in shale," J. Geophys.

63. S. Berg, Y. Gao, A. Georgiadis, N. Brussee, A. Coorn, H. van der Linde, J. Dietderich, F. Alpak, D. Erikson, M. Mooijer-van der Heuvel, J. Southwick, M. Appel and O. Wilson, "Determination of Critical Gas Saturation by Micro-CT," in Annual Symposium of Society of Core Analysts, Pau, France, 2019.

64. P. Mahzari, A. AlMesmari and M. Sohrabi, "Co-history Matching: A Way Forward for Estimating Representative

64. P. Mahzari, A. AlMesmari and M. Sohrabi, "Co-history Matching. A
Saturation Functions," Transport in Porous Media, vol. 125, p. 483-501, 2018.

65. P. Mahzari, U. Taura and M. Sohrabi, "An improved methodology for estimation of two-phase relative permeability functions for heavy oil displacement involving compositional effects and instability," Computational Geosciences, vol. 22, p. 975-991, 2018.

66. C. Chen, M. T. Balhoff and K. K. Mohanty, "Effect of Reservoir Heterogeneity on Primary Recovery and $\mathrm{CO}_{2}$ Huff 'n' Puff Recovery in Shale-Oil Reservoirs," SPE Reservoir Evaluation \& Engineering, vol. 17, no. 03, pp. 404 - 413, 2014.

67. D. Sanchez-Rivera, K. Mohanty, M. Balhoff, "Reservoir simulation and optimization of Huff-and-Puff operations in the Bakken Shale," Fuel, vol. 147, pp. 82-94, 2015.

68. C. Song, D. Yang, "Experimental and numerical evaluation of $\mathrm{CO}_{2}$ huff-n-puff processes in Bakken formation," Fuel, vol. 190, pp. 145-162, 2017.

69. A. Habibi, M. R. Yassin, H. Dehghanpour, D. Bryan, "Experimental investigation of $\mathrm{CO}_{2}$-oil interactions in tight rocks: A Montney case study,” Fuel, Vol. 203, pp. 853-867, 2017.

70. P. Mahzari and M. Sohrabi, "An improved approach for estimation of flow and hysteresis parameters applicable to WAG experiments," Fuel, vol. 197, p. 359-372, 2017.

71. P. Mahzari and M. Sohrabi, " A Robust Methodology To Simulate Water-Alternating-Gas Experiments at Different Scenarios Under Near-Miscible Conditions," SPE Journal, vol. 22, p. 1506 - 1518, 2017. 